Sources of Long-Range Anthropogenic Noise in Southern California and Implications for Tectonic Tremor Detection

\author{
Inbal, Asaf
}

2018-12

Inbal , A , Cristea-Platon , T , Ampuero , J-P , Hillers , G, Agnew , D \& Hough , S E 2018 , '

Sources of Long-Range Anthropogenic Noise in Southern California and Implications for

Tectonic Tremor Detection ' , Bulletin of the Seismological Society of America, vol. 108 , no.

$6,10.1785 / 0120180130$, pp. 3511-3527 . https://doi.org/10.1785/0120180130

http://hdl.handle.net/10138/307688

https://doi.org/10.1785/0120180130

unspecified

publishedVersion

Downloaded from Helda, University of Helsinki institutional repository.

This is an electronic reprint of the original article.

This reprint may differ from the original in pagination and typographic detail.

Please cite the original version. 


\title{
Sources of Long-Range Anthropogenic Noise in Southern California and Implications for Tectonic Tremor Detection
}

\author{
by Asaf Inbal, ${ }^{*}$ Tudor Cristea-Platon, Jean-Paul Ampuero, ${ }^{\dagger}$ \\ Gregor Hillers, Duncan Agnew, and Susan E. Hough
}

\begin{abstract}
We study anthropogenic noise sources seen on seismic recordings along the central section of the San Jacinto fault near Anza, southern California. The strongest signals are caused by freight trains passing through the Coachella Valley north of Anza. Train-induced transients are observed at distances of up to $50 \mathrm{~km}$ from the railway, with durations of up to $20 \mathrm{~min}$, and spectra that are peaked between 3 and $5 \mathrm{~Hz}$. Additionally, truck traffic through the Coachella Valley generates a sustained hum with a similar spectral signature as the train transients but with lower amplitude. We also find that wind turbine activity in northern Baja California introduces a seasonal modulation of $1-$ to $5-\mathrm{Hz}$ energy across the Anza network. We show that the observed train-generated transients can be used to constrain shallow attenuation structure at Anza. Using the results from this study as well as available borehole data, we further evaluate the performance of approaches that have been used to detect nonvolcanic tremor at Anza. We conclude that signals previously identified as spontaneous tremor (Hutchison and Ghosh, 2017) were probably generated by other nontectonic sources such as trains.
\end{abstract}

Electronic Supplement: Seismograms during a transient, decomposition of the large amplitude signal into sequences of repeating patterns, detection statistics in the two stages of the tremor search procedure, velocity amplitude spectra of transients from two collocated borehole-surface station pairs, median weekday-night spectra for all stations in the Plate Boundary Observatory (PBO) Anza network, time variations of root mean square (rms) velocity for all stations in the PBO Anza network, cumulative population and kilometers of railroad on which the allowed speed for freight trains exceeds $50 \mathrm{mph}$, envelopes of vertical ground motions as a function of time, vertical ground motions recorded by the Anza borehole stations, and spectrograms of vertical ground motion and corresponding wind speeds.

\section{Introduction}

The advent of modern seismological networks and processing techniques has greatly facilitated earthquake detection efforts, enabled characterization of seismic events in low-quality data, and provided precise earthquake catalogs used to illuminate active faults (Inbal et al., 2016). Identifying weak signals in noisy data becomes progressively more difficult as the overlap in the frequency content, duration, and amplitude of the target signal and the ambient noise field increase. This issue is accentuated in urban environments, where anthropogenic sources induce signals that carry ample

*Also at the Berkeley Seismological Laboratory, University of California, Berkeley, California 94703.

Also at the Seismological Laboratory, California Institute of Technology, Pasadena, California. energy in the $1-$ to $10-\mathrm{Hz}$ frequency band often used to observe microseismic activity (Riahi and Gerstoft, 2015). Thus, detection capabilities in densely instrumented urban areas are low compared with nearby, less well-instrumented areas. For example, the magnitude of completeness of earthquake catalogs for the metropolitan Los Angeles (LA) area and the adjacent Anza region are $M \approx 2$ and $M \approx 1$, respectively (Hutton et al., 2010). Because station density in Anza is four to five times smaller than within the LA basin, the dramatically better detection capability in Anza is due to a much lower noise level, which is mainly the result of sparse population. The 1- to 10-Hz noise amplitudes in Anza are about 50 times lower than within the city of Long Beach, one of the noisiest and most seismically active regions in the LA basin. The installment of the Plate Boundary (PB) borehole 
network in Anza, on which noise amplitudes are about a factor of 10 smaller than on the surface seismometers (Barbour and Agnew, 2012), further enables the detection of many $M \approx 1$ earthquakes in that area (e.g., Meng and Peng, 2014).

In most cases, the signal caused by an $M \geq 2$ earthquake will exceed anthropogenic noise levels in the $1-$ to $10-\mathrm{Hz}$ band. Even smaller magnitude earthquakes will give rise to distinct impulsive arrivals that are coherent across a regional network, which greatly facilitates both event discrimination and association stages. This, however, is not generally true for tectonic tremors. This class of tectonic events was first recognized and characterized in Japan in 2002 (Obara, 2002) and has subsequently been the target of extensive further study in Japan and elsewhere (see Shelly et al., 2006; Rubinstein et al., 2009, for reviews). Tectonic tremors are associated with emergent, long-duration, low-amplitude seismic signals. They are distinct from the harmonic tremor that has long been observed in active volcanic settings (e.g., Aki et al., 1977). The signals generated by tectonic tremor are similar in many respects to those generated by anthropogenic sources such as vehicle traffic, machinery, or wind farms.

The initial identification of tremor was based on the observation of transients appearing across a high-sensitivity seismic network (Obara, 2002). The prolonged nature of tremor signals and the absence of clear apparent phases complicated efforts to determine precise locations until later work identified so-called low-frequency earthquakes (LFEs) within tremor: these events have identifiable body-wave arrivals that are depleted in high-frequency energy relative to waves generated by tectonic earthquakes of the same size (e.g., Shelly et al., 2006). Tremor is now thought to be composed, wholly or in part, of many LFEs (Shelly et al., 2007). Because LFEs produce weak signals closely spaced in time, they generally cannot be identified using standard seismic event detection methods but rather require more sophisticated approaches such as autocorrelation and template-based stacking of identified LFEs (e.g., Gibbons and Ringdal, 2006; Ide et al., 2007). The main advantage of such methods is their simplicity; when the level of autocorrelation within the network exceeds some threshold, a positive detection is declared. However, as with any other detection approach, matched-filter techniques have their own limitations. An implicit assumption built into those methods is that the analyzed record is composed of a superposition of multiple nearly identical signals arriving at the same station at a varying rate. In their simplest form, autocorrelation-based techniques do not make any assumptions regarding the physics of the target wavefield (i.e., ray parameter, particle motion, radial vs. tangential component amplitudes) but rather attempt to validate these features after a positive detection has been made. As will be shown here, signals induced by anthropogenic sources around Anza, which are typically the result of some quasi-stationary superficial mechanical processes, are erroneously labeled as tectonic tremors when subjected to a conventional autocorrelation-based detector.
Tremor investigations have generated significant interest because of the opportunity they offer to better understand the mechanics of fault systems and, potentially, the nature of earthquake nucleation and the earthquake cycle (e.g., Ariyoshi et al., 2012). Since 2002, studies of high-quality seismic data have found tremors not only in Japan but also in other subduction zones, including Cascadia, Alaska, Costa Rica, and Taiwan (see Rubinstein et al., 2009). Tremors triggered by dynamic strains associated with teleseismic waves have been reported along some subduction zones, as well as in other regions (e.g., Gomberg et al., 2008; Peng and Chao, 2008; Peng et al., 2009; Fry et al., 2011), including along the San Jacinto fault (SJF) in southern California (Wang et al., 2013). Along continental transform faults, spontaneous tremors (i.e., not triggered by seismic waves) have been identified in only two regions-the San Andreas fault in central California (Nadeau and Dolenc, 2005) and along a deep extension of the Alpine fault in New Zealand (Wech et al., 2012).

Identifying what controls the occurrence of tectonic tremors by comparing different source environments and understanding their relation to other seismic and aseismic phenomena have motivated attempts to detect tremor in other regions, including southern California. The SJF has been an attractive target for investigation because of the reported presence of triggered tremor (Gomberg et al., 2008; Wang et al., 2013), its high rate of low- to moderate-magnitude seismicity (e.g., Wesnousky, 1994), and the high density of stations caused by the expectation that a significant earthquake will occur in the future in the Anza seismic gap (Thatcher et al., 1975; Sanders and Kanamori, 1984). Furthermore, the observation of triggered slow-slip events in the lower half of the seismogenic zone near the Anza gap (Inbal et al., 2017) suggests the possibility of tremors induced by slow slip occurring near the boundary between partially creeping and locked fault regions, by analogy to the tremor source region near Parkfield (e.g., Shelly and Hardebeck, 2010). However, unlike Parkfield, the Anza region is surrounded by nontectonic sources that generate loud tremor-like signals contaminating the seismic records (Meng and Ben-Zion, 2018). It is therefore instructive to assess whether the signal-to-noise ratio (SNR) in Anza, which allowed for a 1-magnitude-unit reduction in the completeness of the seismicity catalog relative to more densely instrumented faults nearby, will also enable tremor detection.

Recently, Hutchison and Ghosh (2017; hereafter, HG17) reported on five episodes in June 2011, which they attribute to the occurrence of deep spontaneous tectonic tremor along the central section of the SJF near Anza. Our goal here is to reevaluate HG17 reports in light of an investigation of cultural noise in the area. Li et al. (2018) found that the duration and spectral content of train-induced signals observed at a short range $(<20 \mathrm{~km})$ are similar to the ones usually associated with tectonic tremors. We also find low-amplitude transients on borehole seismometers near Anza whose duration is consistent with tremor observed in other regions and whose spectral range overlaps with the 2- to $8-\mathrm{Hz}$ band 
(a)

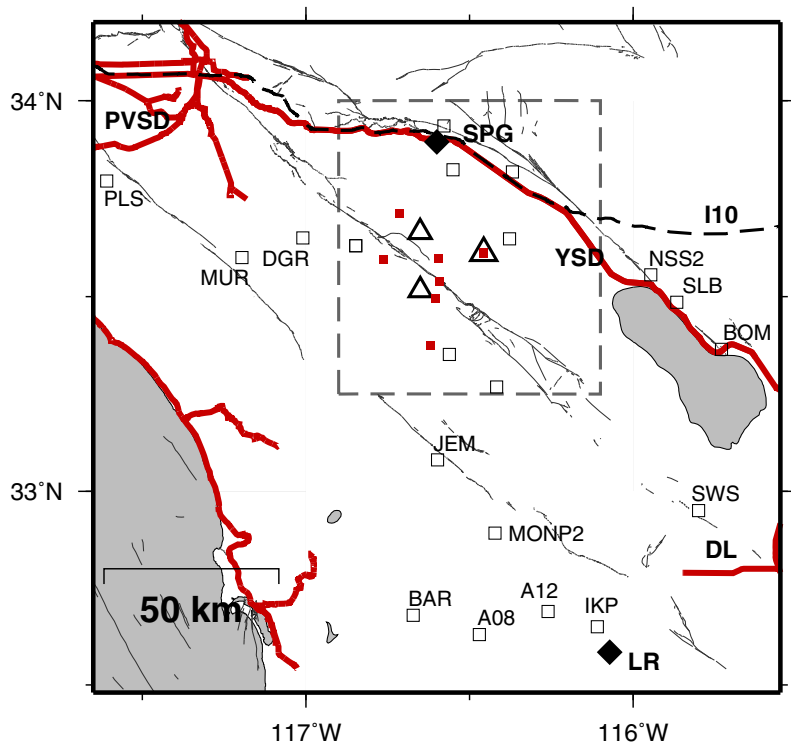

(b)

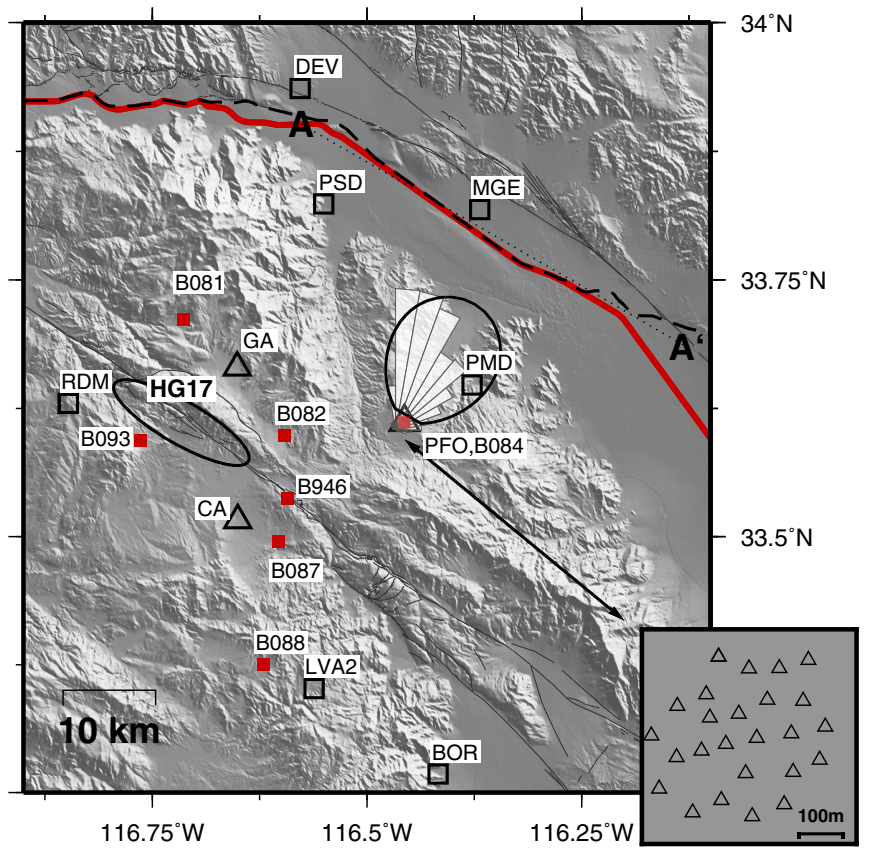

Figure 1. Location map showing the seismic stations used in our analysis, including Plate Boundary (PB) borehole instruments (white squares) and broadband AZ and CI stations in the Coachella Valley, Anza, and the Imperial Valley (solid squares). Seismic arrays ZZ.PFO, ZZ.CA, and ZZ.GA are shown by black triangles. Mapped faults are shown in dark gray. (a) Regional map. Major railways and the Interstate-10 (I-10) highway are shown by the solid thick and black dashed curves, respectively. Wind farms are indicated by black diamonds. YSD, Yuma Subdivision; DL, Desert Line; PVSD, Perris Valley Subdivision; LR, La Rumorosa wind farm; SGP, San Gorgonio Pass wind farm. The dashed rectangle represents the area presented in (b). (b) The central section of the San Jacinto fault (SJF) in Anza. The segment Hutchison and Ghosh (2017) report hosted tectonic tremors in June 2011 is shown with the ellipse labeled HG17. The rose diagram shows the back azimuth of wavefronts during the 100 strongest transients detected by the ZZ.PFO array (collocated with broadband station B084). Dotted line A-A' indicates the portion of the YSD for which the predicted train noise amplitude is larger than the ambient noise amplitude at B084. The black curve overlaying the histogram shows the predicted amplitude at Piñon Flat Observatory (PFO) as a function of azimuth to a source moving along line A-A'. The PFO array configuration is shown in the inset map. The color version of this figure is available only in the electronic edition.

usually associated with tectonic tremors. However, the spectral shape of signals studied here is more peaked between 3 and $4 \mathrm{~Hz}$ (trains and trucks) or contains several sharp peaks between 1 and $5 \mathrm{~Hz}$ (wind turbines). Cultural sources in Anza may generate tremor-like signals observed at distances as far as $100 \mathrm{~km}$ away from the source and are hence termed long-range sources in this article.

To better understand the origin of transient human-made signals and the potential pitfalls they pose to studies aiming to detect tectonic tremors in Anza, we analyze data from a smallaperture array deployed at the Piñon Flat Observatory (PFO) in 2010 (the MAOTECTRA experiment, network code ZZ [2011-2011]; see Data and Resources) and from permanent stations in several networks: the Southern California Seismic Network (code CI), the Red Sísmica del Noroeste de México (BC), the surface stations of the Anza network (AZ), and the borehole stations of the PB network (Fig. 1). The PB stations are particularly valuable because of their low noise level (Barbour and Agnew, 2012). We examine observed transients and characterize the background noise, which allows us to identify the main cultural sources that contribute to apparently noteworthy (quasi-harmonic and/or low-frequency) signals. Longduration high-frequency signals caused by cultural sources (Latorre et al., 2014) or small regional earthquakes (Caffagni et al., 2015; Zecevic et al., 2016) have been misidentified as tectonic tremors in the past. Such signals are frequent in Anza, and they may also be mislabeled as tectonic tremors. Therefore, after we gain better control of the background noise level and distribution of cultural noise sources in Anza, we attempt to assess the performance of the tremor detection approach of HG17.

Previous studies suggest that train-induced signals may be used to infer the medium's shallow attenuation properties (Fuchs and Bokelmann, 2018) or for interferometric structural imaging purposes (Nakata et al., 2011; Quiros et al., 2016; Dou et al., 2017). In this study, we show that cultural noise sources in Anza probe depths intermediate to the depth ranges accessible to borehole and conventional seismic investigations. Thus, signals generated by these cultural sources provide a unique opportunity to refine the regional attenuation versus depth model.

\section{Seismic Noise Induced by Trains}

\section{Temporal Characteristics}

Much of the episodic tremor-like noise comes from the heavy freight trains operated by the Union Pacific Railroad over its Yuma Subdivision (hereafter, YSD) as they pass 
through the Coachella Valley (Fig. 1; see also Fig. 8f for summary of rail traffic). Many of these are unit trains of doublestacked containers, weighing up to $7000 \mathrm{~kg} / \mathrm{m}$ of length and with lengths of 1-1.5 km. Schedules for these trains are not publicly available, so to investigate the nature and timing of signals generated by them, we use CI seismic stations near the tracks to record ground vibrations induced by each train. We focus on data from CI stations at distances of 1-10 km from the track (black squares in Fig. 1). To highlight train noise, we bandpass filtered the data between 2 and $8 \mathrm{~Hz}$ and plotted the time series from stations located from south to north along the railroad. Figure 2 shows a record section with four clearly observed transients at the CI station nearest the track.

We analyze the properties of the wavefield generated by the identified transients using a small-aperture array we deployed at PFO, collocated with borehole station PB.B084 (see Fig. 1b). The array operated between November 2010 and July 2011; we also operated arrays at two other locations in Anza (GA and CA) for a shorter time interval between April and July 2011. Each array consisted of 15-25 sensors with average spacing of about $60 \mathrm{~m}$. The array geometries were specifically designed to study signals with frequencies between 1 and $10 \mathrm{~Hz}$. In this study, we use the recordings from the PFO array at which the transients are most clearly observed. We analyze the array data applying a coherency stacking technique (Frankel et al., 1991; Fletcher et al., 2006) to infer the ray parameters under the assumption of a single incoming plane wave. Data are filtered between 2 and $8 \mathrm{~Hz}$, and the back azimuth and apparent velocity are computed for 20 -s-long windows with 50\% overlap. In Figure 3, we present the results of applying the array analysis to the interval containing the four induced transients shown in Figure 2. In the array data, these correspond to periods of increased amplitude (Fig. 3a) and coherence (Fig. 3b). The observed transients are characterized by a similar duration of about $1000 \mathrm{~s}$, a systematic temporal evolution of back azimuth from near north to near northeast, and an apparent velocity of $\sim 2500 \mathrm{~m} / \mathrm{s}$. The temporal evolution of back azimuth during each transient (Fig. 3c) is attributed to trains along the YSD in the Coachella Valley. Projecting the back azimuths on the railroad track or on Interstate-10 (I-10) to estimate the velocity of the sources, we find speeds of about $30 \mathrm{~m} / \mathrm{s}$, consistent with the velocities we infer from recordings at stations located along the YSD (Fig. 2).

The original objective of this study was to identify spontaneous tectonic tremors along the SJF. To this end, we developed a hierarchical algorithm for transient detection and waveform decomposition and applied it to 2 yrs of continuous ground-motion data recorded between 2008 and 2009 (see the (E) electronic supplement to this article for full description of the method and the results). The initial transient detection stage is based on the similarity between envelopes of velocity measured at the PB borehole sites, which is a commonly used approach for tremor detection (e.g., Obara, 2002; Wech and Creager, 2008). We select the 100 strongest transients identified with this approach during 2011 and ap-

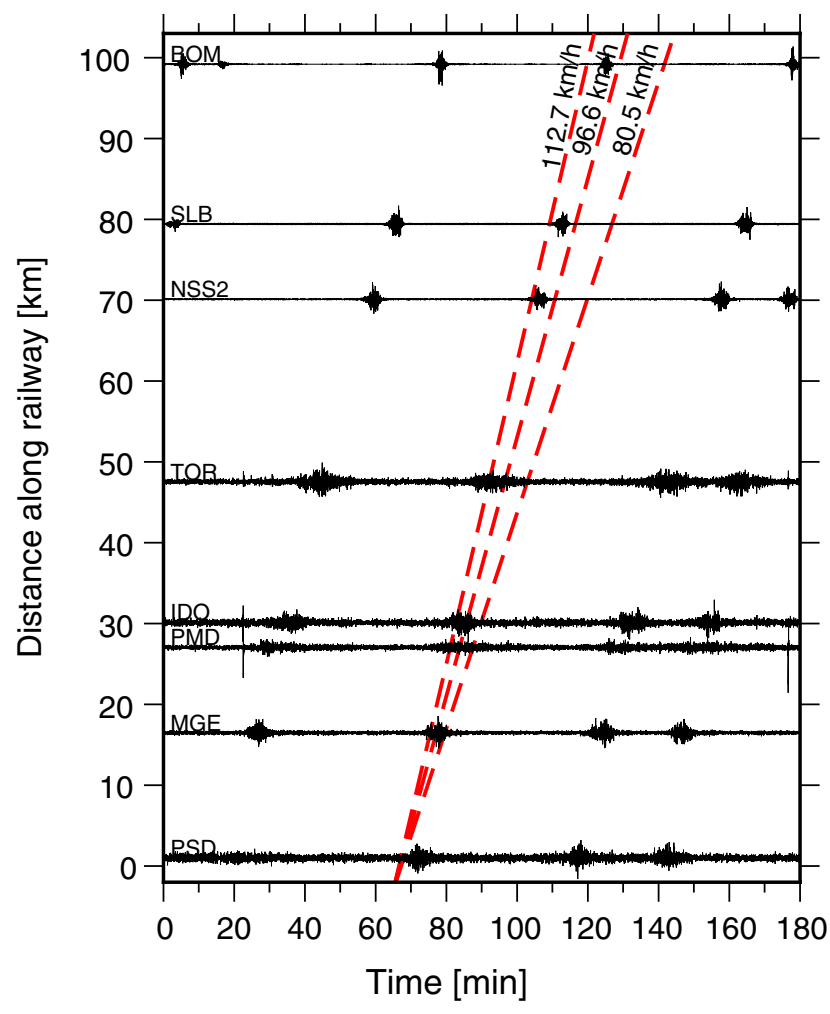

Figure 2. Horizontal motions (north-south component) recorded by stations aligned from northwest to southeast along the YSD railroad (thick curve in Fig. 1a,b). Time starts at 06:48:20 UTC on 19 May 2011. Station names are indicated above each trace. Dashed curves are for speeds of 80.5, 96.6, and $112.7 \mathrm{~km} / \mathrm{hr}$ (50, 60, and $70 \mathrm{mph}$, respectively). Traces are not to scale. The color version of this figure is available only in the electronic edition.

ply the array processing scheme to these data. Figure $1 \mathrm{~b}$ shows a rose plot histogram of the back azimuths estimated for the selected transients. The impinging energy is consistently characterized by a north-northeast-east back azimuth pointing toward the railroad in the Coachella Valley (Fig. 1). Clearly, the conventional low-resolution transient detection technique yields many false (nontectonic) detections when applied on recordings from the sensitive network in Anza. This behavior is further discussed in the Signals Identified by Hutchison and Ghosh (2017) section.

Although large wind farms operate in the Coachella Valley, the Laguna Mountains east of San Diego, and the Sierra Juárez in northern Baja California, they are located to the north-northwest and south of the back-azimuth range shown in Figure 1b. Wind turbines would also not produce migrating sources but do appear to modulate the amplitude of 1- to 5-Hz energy in Anza, as discussed in the Seismic Noise Induced by Wind Farms section. The array analysis results point to vehicle traffic noise, with back azimuths roughly in the direction of the nearest section of the YSD and highway I-10, the main traffic arteries along the Coachella Valley. Freight trains, being more than 100 times the mass of trucks, are the most obvious candidate source. As reported by the Federal Railroad Administration's Rail Crossing Locator 
(a)

(b)
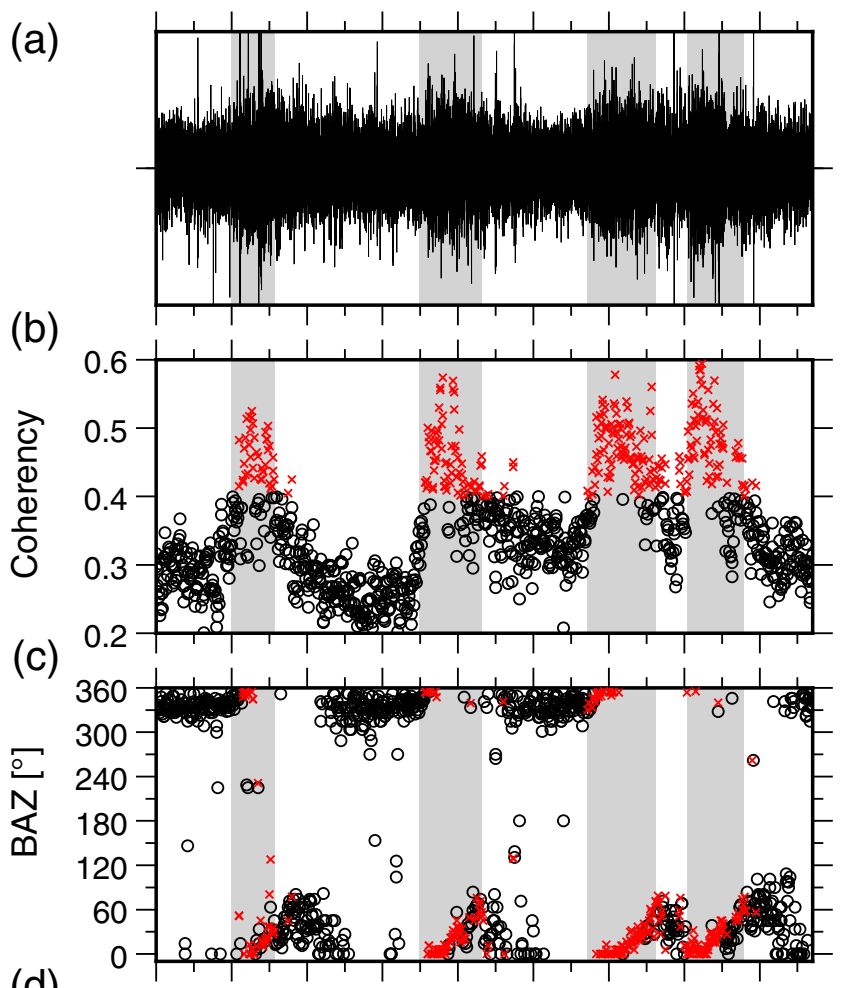

(d)

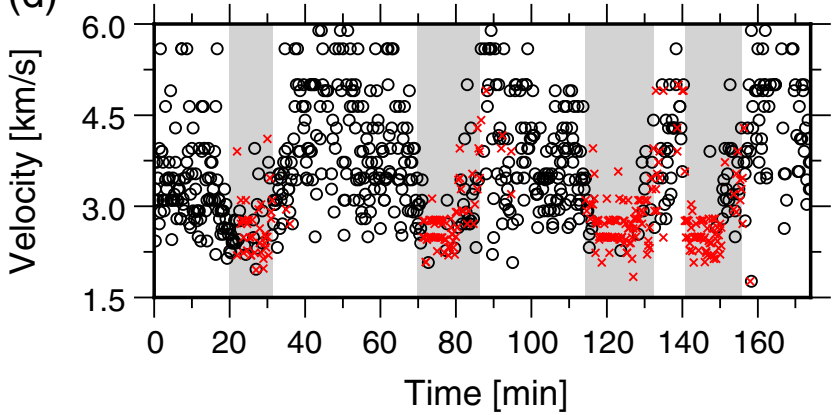

Figure 3. Train-induced ground motions recorded by a temporary seismic array in the PFO. Time (in seconds) starts at 06:48:20 UTC on 19 May 2011. (a) Ground velocity of the north-south component at one of the array sensors. Data are bandpass filtered between 2 and $8 \mathrm{~Hz}$ and scaled by the maximum absolute value. (b) The mean coherency, (c) back azimuth, and (d) apparent velocity. Gray windows indicate periods with strong train traffic noise. Crosses indicate estimates with mean coherency $>0.4$, a threshold above which train-induced signal begins to exceed the background noise in the seismogram. The color version of this figure is available only in the electronic edition.

mobile application, an average of 33 freight trains move daily through the YSD in the northern Coachella Valley, between North Palm Springs and Mecca, at speeds typically not much slower than $30 \mathrm{~m} / \mathrm{s}$ and maximum speeds of $35 \mathrm{~m} / \mathrm{s}$, as indicated from time tables. The speed limit for trucks is $25 \mathrm{~m} / \mathrm{s}$; actual speeds are often somewhat higher.

\section{Spectral Characteristics}

We further consider the spectral signature of the transients observed in the Coachella Valley using 20-min windows centered on individual transients. This time duration is comparable to the typical transient duration observed at the PB borehole stations. We smoothed the spectra with a moving average over 31 sample points $(\approx 0.5 \mathrm{~Hz}$ width). The spectra are found to be peaked near $4 \mathrm{~Hz}$ (Fig. 4a).

We find that low-amplitude transients generated by trains moving along the YSD (with typical SNR of 2-3) are observable on the borehole stations in Anza by visual inspection of filtered seismograms in PB borehole stations B084, B081, B082, B946, and B093. The loudest transients are observed more than $40 \mathrm{~km}$ away from the railroad at $\mathrm{PB}$ borehole sites B087, and under favorable SNR conditions, they may also be observed at borehole site B088, located more than $50 \mathrm{~km}$ from the railroad. Only large transients are visible on surface stations located more than $50 \mathrm{~km}$ from the railroad. The coarse detector based on envelope cross correlation (ECC) is sensitive to even weaker transients (Fig. 4b and (E) Figs. S1-S4). Their typical duration is about $20 \mathrm{~min}$, and their timing generally corresponds to the times when trains are passing through the Coachella section of the YSD, nearest Anza. The spectra of the transients recorded at the borehole stations are peaked from 3 to $4 \mathrm{~Hz}$ (Fig. 4a), similar to the spectra of train-induced transients recorded in the Coachella Valley. The borehole spectra are more strongly peaked than spectra observed in the Coachella Valley. This is consistent with expectations given the $2-\mathrm{Hz}$ corner of the borehole instruments and the preferential attenuation of high frequencies along the path between the valley and Anza.

\section{Surface-Wave Attenuation}

We use the amplitude of the transients seen on the borehole stations to estimate attenuation in the Anza region. Assuming the transient signals are composed of high-frequency Rayleigh waves affected by attenuation, their amplitudes $\tilde{A}$ are predicted to decay as a function of distance $r$ as

$$
\tilde{A} \propto e^{-\pi f r / V Q} / \sqrt{r},
$$

which is commonly written as

$$
\tilde{A} \propto e^{-\pi f t^{*}} / \sqrt{r},
$$

in which $f, V$, and $Q$ are frequency, wave velocity, and the attenuation quality factor, respectively. The parameter $t^{*}$ is an attenuation time scale that Anderson and Hough (1984) equate to the observed spectral decay parameter $\kappa(r)$, and is the result of integrating $1 / V Q$ along the ray path, with $\kappa(0)$ representing the site's seismic attenuation. As an approximation, we assume a frequency-independent $Q$, which is a reasonable assumption given the narrow bandwidth of the signals (Fig. 4a).

To determine the value of $Q$ in Anza, we model the observed amplitudes as the sum of the transient signal and uncorrelated noise present in the data. We write the transient amplitude as

$$
A=\tilde{A}+\epsilon,
$$



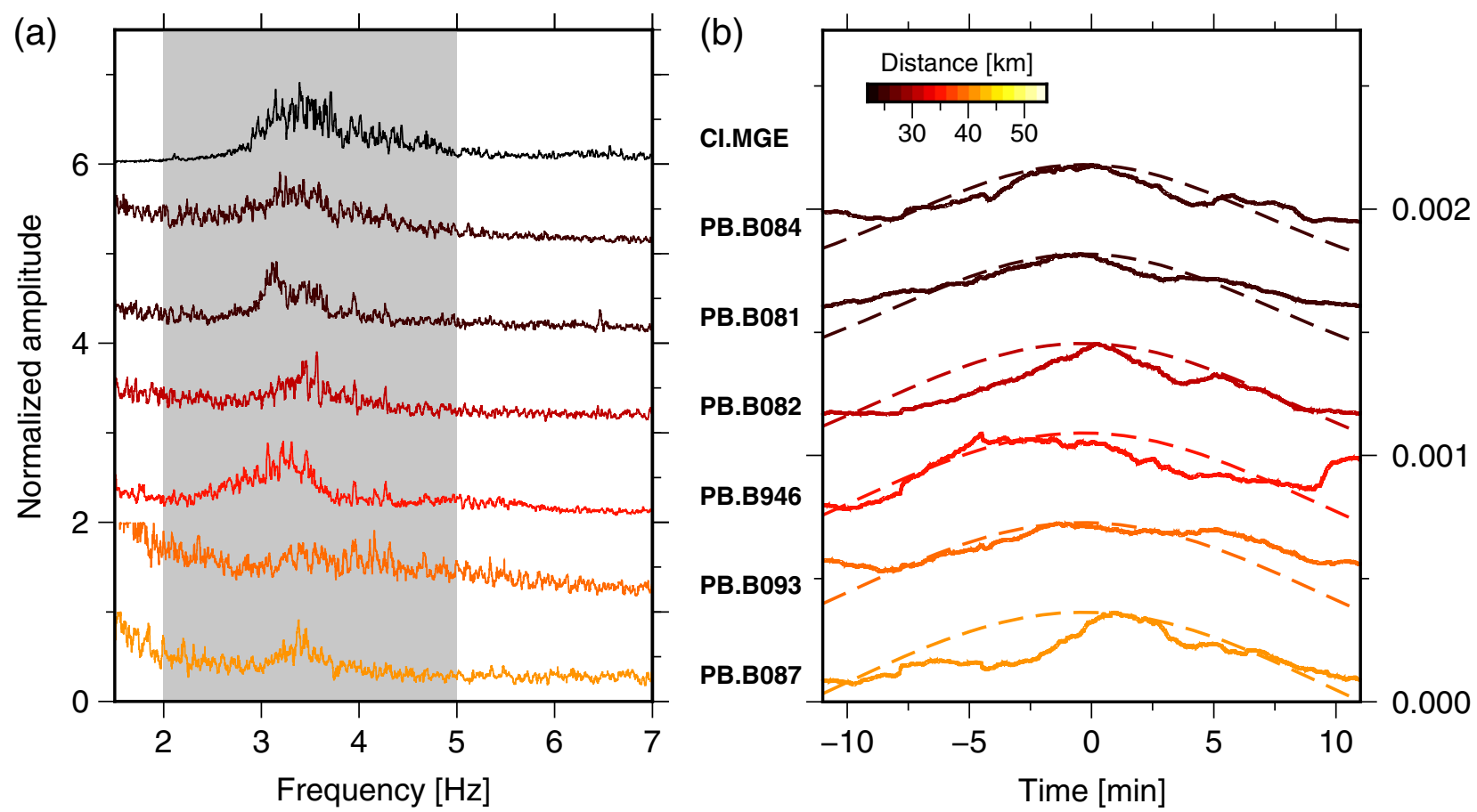

Figure 4. Spectral and temporal analysis of induced ground velocities (horizontal north-south channels) caused by train passing on 29 November 2012. Measurement window is between 12:44:00 and 13:07:00 UTC. The horizontal bar indicates distance to the YSD railroad. CI, California Integrated Seismic Network surface station; PB, Plate Boundary borehole station. (a) Spectral amplitudes. The gray rectangle highlights the frequency band with peak near-railway train-induced motions. A smoothing window of 31 points (- width) was applied to the spectra, followed by normalization by the maximum amplitude in the 2- to 5-Hz frequency band. (b) Observed (solid curve) and simulated (dashed curve) envelops. Raw envelope amplitudes are normalized by the maximum observed at station MGE and represent vertical energy in the 2- to 5-Hz frequency band. Modeled envelopes computed using the method described in the Surface-Wave Attenuation section. The color version of this figure is available only in the electronic edition.

in which $A$ is the maximal spectral amplitude in the 2- to $5-\mathrm{Hz}$ frequency band in a time window containing the transient and $\epsilon$ is the median spectral amplitude in the same frequency band $1 \mathrm{hr}$ preceding the transient. To remove the common effect of the source on all stations, we normalize $\tilde{A}$ by the observed transient amplitude at station MGE (located $2 \mathrm{~km}$ from the railroad). From the observed decay of the spectral amplitude at $3.5 \mathrm{~Hz}$ of transients detected at the borehole stations (Fig. 5), we find that a $Q$-value in the range between 20 and 50 is roughly consistent with the observations across the borehole array. We also find that average surface-wave amplitudes in station B946, which is located within a highly damaged zone (e.g., Qin et al., 2018), and stations B087 and B093, located to the southwest of the SJF, are systematically higher than the predictions of our simplified 1D attenuation model. Understanding possible interactions between train-induced surface waves and the local geological structure likely requires a more elaborated model that accounts for complex 3D propagation effects and is outside the scope of this article.

Previous studies estimated local and regional attenuation at Anza. Hough and Anderson (1988) use data from surface Anza stations to estimate frequency-independent shear-wave $Q$-values of $\sim 500$ in the upper $5 \mathrm{~km}$. Using shallow logging techniques at surface Anza stations KNW and PFO, Fletcher

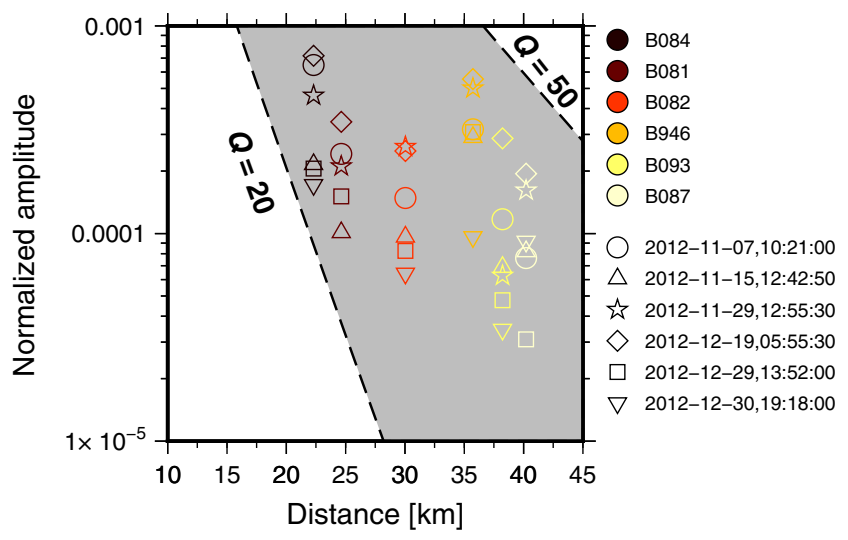

Figure 5. Spectral amplitude of train-induced transients as a function of distance between Anza borehole stations to the nearest point on the railroad. The transient observation time (UTC) is indicated by the symbol shape as follows: circle, 7 November 2012 10:21:00; triangle, 15 November 2012 12:42:50; star, 29 November 2012 12:55:30; diamond, 19 December 2012 05:55:30; square, 29 December 2012 13:52:00; and inverted triangle, 30 November 2012 19:18:00. The gray area highlights the expected decay of attenuated surface waves at $4 \mathrm{~Hz}$, assuming a group velocity of $2 \mathrm{~km} / \mathrm{s}$ and $Q$ in the range between 20 and 50. The color version of this figure is available only in the electronic edition. 
et al. (1990) estimate $Q$-values of $\sim 10$ in the upper $50 \mathrm{~m}$. The transients generated by trains have a predominant frequency of $\sim 3 \mathrm{~Hz}$, assuming a velocity of $3 \mathrm{~km} / \mathrm{s}$, which suggests a skin depth on the order of $500 \mathrm{~m}$, intermediate between the two depth ranges for which attenuation has been estimated in previous studies.

The $Q$-value estimated in this study is an effective average path $Q$ over the depth sampled by the presumed high-frequency surface waves. Because attenuation is estimated from relative amplitudes at borehole stations, the value will not reflect attenuation with the upper 150-200 m. Although it is not the focus of this study, our result can be compared with results for other depth ranges to refine the average $Q(z)$ model in the Anza region. Our $Q$ estimate of 35 for depths between 200 and $500 \mathrm{~m}$ implies that attenuation over this depth range will contribute a $t^{*}$ of $\sim 0.003$ given velocity structure constrained from borehole and regional data (Fletcher et al., 1990; Yang et al., 2012). Assuming the same $Q$-value for depths between 50 and $200 \mathrm{~m}$, attenuation over this interval will contribute an additional $t^{*}$ of 0.0057 . A $Q$-value of 35 over $50-500 \mathrm{~m}$ would thus correspond to a $t^{*}$ of 0.0087 from this depth interval. In contrast, Fletcher et al. (1990) estimated $t^{*}$ for the upper $50 \mathrm{~m}$ at stations $\mathrm{KNW}$ and $\mathrm{PFO}$ to be in the 0.003 - to $0.004-\mathrm{s}$ range. Estimating $t^{*}$ from the observed spectral decay parameter $\kappa(0)$ (e.g., Anderson and Hough, 1984), Hough and Anderson (1988) show that values of $\kappa(0)$ at Anza are low and difficult to estimate precisely. Campbell (2009) estimates an average $\kappa(0)$ of $0.007 \mathrm{~s}$ for the six Anza stations where hard rock is encountered at relatively shallow depths. The discrepancy between this result and our slightly higher estimated $t^{*}$ for the depth interval 50-500 likely reflects the uncertainties of both estimates, but suggests that attenuation within the upper $500 \mathrm{~m}$ at Anza contributes most of the observed $t^{*}$ value. Although the calculations are simplified, they reveal that the $Q(z)$ structure at Anza increases more steeply with depth than the models estimated by Hough and Anderson (1988), which could only resolve the integrated attenuation over the top $5 \mathrm{~km}$.

The results of our attenuation analysis allow us to identify the stretch of the YSD where train traffic most efficiently generates noise seen on the Anza borehole stations. Making use of the calibrated amplitude-distance relation (equation 1) and assuming a single train running along the Coachella Valley railroad with speed $c=22 \mathrm{~m} / \mathrm{s}$ acting as a steady source of seismic waves, we can calculate a transient envelope shape in Anza. As a further simplification, we represent the segment of the railroad that lies nearest station B084 as a straight line (roughly between stations DEV and NSS2, indicated by segment $\mathrm{A}-\mathrm{A}^{\prime}$ in Fig. 1b). We obtain a time-dependent signal amplitude by setting $r=\sqrt{d^{2}+(c t)^{2}}$ in equation (1), in which $d$ is the nearest distance between each station and the railroad and $t$ is time relative to the passage of the train by the nearest point. The theoretical envelope is of comparable duration and shape as the transients observed at the borehole stations (Fig. 4b). From array analysis of multiple train-induced transients recorded by the PFO array (Fig. 1b), we infer that the dominant energy is generated along a section of track somewhat shorter than the extent of the track along $\mathrm{A}-\mathrm{A}^{\prime}$. We speculate that this might be due to path effects, due to the fact that the train track departs from the assumed linear shape, or due to variations in train speeds. Nonetheless, our results (Fig. 4b) demonstrate a good general agreement between the predicted and observed transient durations.

\section{Seismic Noise Induced by Wind Farms}

The Anza region is also close to the San Gorgonio Pass (SGP) wind farm, the second largest wind farm in California. The SGP, which has operated since the 1980s, contains more than 2000 wind turbines distributed in the Coachella Valley to the north of Anza. A second wind farm is located near the town of La Rumorosa (LR) in northern Baja California, Mexico, about $100 \mathrm{~km}$ from Anza (Fig. 1a). The LR high wind power capacity is the result of strong winds that blow primarily during the winter and spring times in northern Baja California (see Data and Resources for wind speed data sources). Although it contains only 50 wind turbines, the LR wind farm energy capacity in 2016 was about $23 \%$ of the SGP capacity (U.S. Energy Information Administration).

Under optimal wind speed and direction, the blades are designed to rotate at a constant rate of $17.7 \mathrm{rpm}$. Actual rotation rates may however vary because of changes in wind speeds or the nacelle orientation. The blade rotation transmits force via the base of the tower to the ground and hence generates elastic waves. The spectra of the induced motions consist of stationary peaks frequently associated with the tower natural frequencies and nonstationary peaks caused by the time-dependent blade rotation speed (Saccorotti et al., 2011). Observed motions associated with blade rotations are strongest in the 1 - to $5-\mathrm{Hz}$ band. In some cases, the wind-farminduced motions have been observed out to about $18 \mathrm{~km}$ away from the wind farm barycenter (Schofield, 2001; Saccorotti et al., 2011). A recent study by Marcillo and Carmichael (2018) suggests that seismic-induced noise generated by wind farm activity in Texas may be recorded by stations located up to about $100 \mathrm{~km}$ away from the wind farm.

Seismic-induced noise generated by wind farm activity has been shown to hinder microearthquake monitoring at distances $<10 \mathrm{~km}$ from the wind turbines (Neuffer and Kremers, 2017). Here, we are interested in examining whether wind turbine activity in LR may modulate the ground-motion amplitudes at sites located tens of kilometers away from LR. Between 2012 and 2016, the number of towers in LR has increased by a 10-fold. This allows us to assess the effect of wind turbine activity in LR on the amplitude of highfrequency $(1-8 \mathrm{~Hz})$ seismic noise in Anza. This analysis is particularly important in light of plans to increase the LR energy capacity by about a 10-fold in the next years (Sunrise Powerlink Project, State of California Public Utilities Commission; see Data and Resources).

Figure 6 presents the envelopes of vertical ground velocity in Anza. At a time scale of several hours, both wind blow- 
(a)

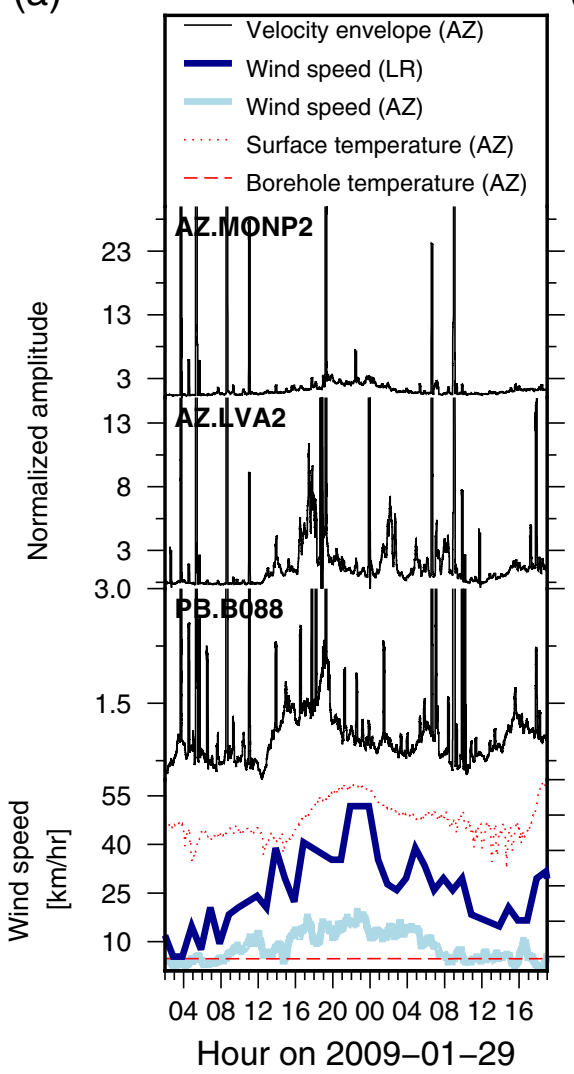

(b)

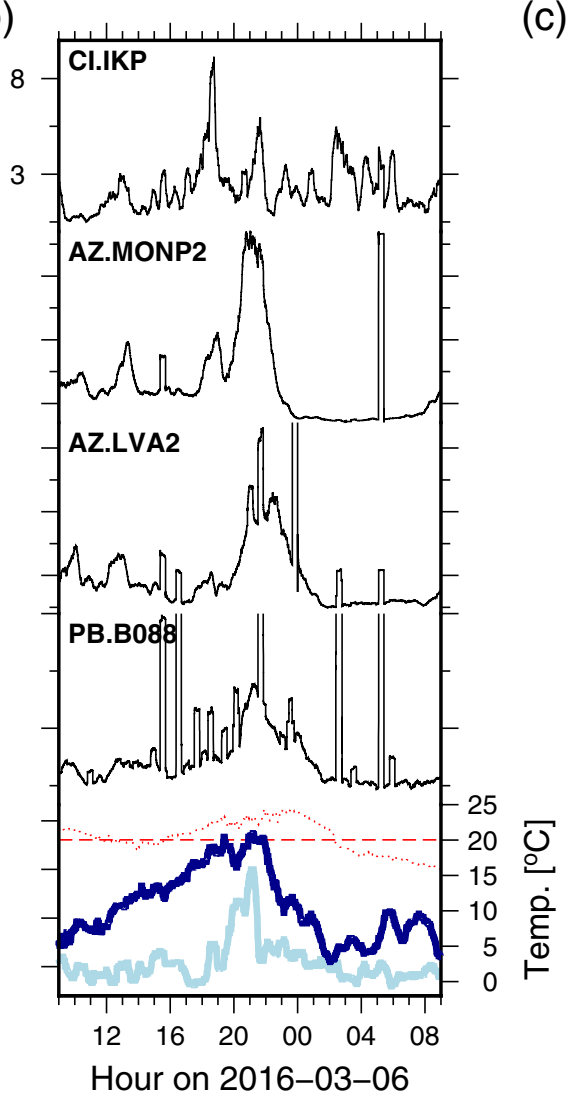

(c)

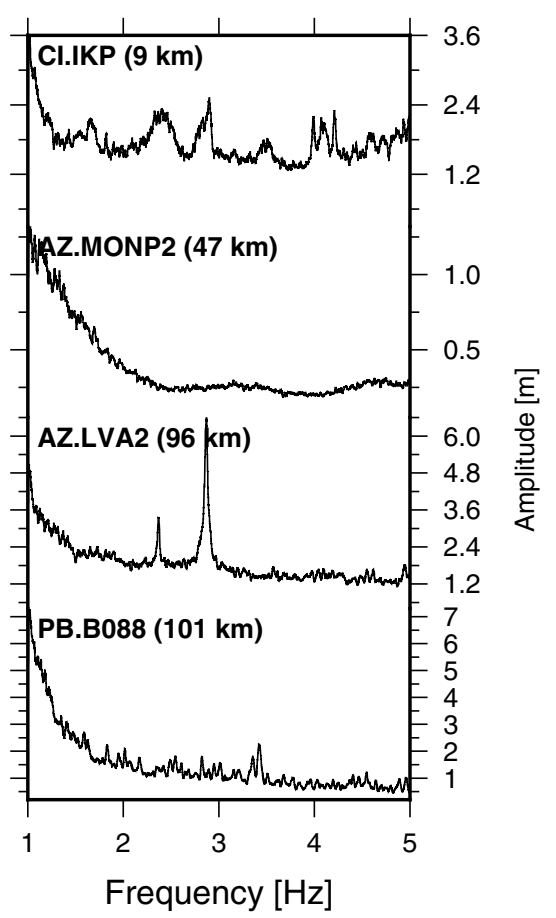

Figure 6. Envelopes and spectra of ground velocity as a function of hour of day (UTC) during episodes with strong winds near the LR wind farm (indicated by a black diamond in Fig. 1a). Raw traces were filtered between 1 and $5 \mathrm{~Hz}$, squared, smoothed with a 10-min running average window, and normalized by the three-day median amplitude. The bottom plots on $(\mathrm{a}, \mathrm{b})$ represent the wind speed in LR and in Anza (AZ), the air temperature in Anza, and the downhole temperature in site B088, respectively, with the line styles indicated in the legend in (a). Station names are indicated above each trace (locations are shown in Fig. 1). (a) 29 January 2009; (b) 6 March 2016, after installation of 50 wind turbines in LR; (c) spectral amplitudes of peak observed ground velocities. Analyzed time window is between 6 March 2016 20:00:00 and 6 March 2016 23:59:59. Distance to LR (in kilometers) is indicated in the brackets near the station name. See () Figure S11 (available in the electronic supplement to this article) for spectrogram analysis of the interval presented in $(b, c)$. The color version of this figure is available only in the electronic edition.

ing on the stations and local temperature fluctuations are expected to modulate observed noise amplitudes. Air temperature and wind speeds may be correlated, which makes difficult separating their contribution to the observed records. However, for the 29 January 2009 episode shown in Figure $6 \mathrm{a}$, which was recorded before the installation of wind turbines in LR, the correlation between wind speed in LR and the amplitude of ground motion in Anza appears to be poor. The timing of peak ground-motion amplitude in surface station LVA2 and borehole station B088 is offset from the peak wind velocity by $7-8 \mathrm{hrs}$. This suggests that factors such as local winds or temperature fluctuations are controlling the amplitude of seismic motions recorded at the surface, as observed, for example, in station LVA2 on 29 January 2009 between 18:00 and 21:00 in Figure 6a.

The modulation of ground-motion amplitudes at some of the Anza sites is highly accentuated by activity of the LR wind turbines. This is mostly visible after 2014, when most of the wind turbines in LR had been installed. One ex- ample is presented in Figure 6b, which shows the envelope of vertical ground velocity in Anza on 6 March 2016 (see also spectrogram analysis in (E) Fig. S11). Unlike the episode shown in Figure 6a, the ground velocity envelopes in stations LVA2 and B088 are well correlated with wind speeds measured near LR and not with local air temperature or wind speed in Anza. Also under wind speeds comparable to the ones observed on 29 January 2009, station MONP2, located about $47 \mathrm{~km}$ away from LR, exhibits peak amplitudes that are about 25 times the three-day median amplitude. The modulation at that station on 29 January 2009 is minor and amounts to no more than three times the three-day median amplitude at the time of peak wind speeds in Anza (Fig. 6a). Energy at frequencies $>5 \mathrm{~Hz}$ recorded by station LVA2 during the 6 March 2016 episode is larger than the amplitude of the 1- to 5-Hz frequency band (Fig. S11), suggesting a local noise source near that site. Seismic motions recorded at borehole station B088, whose SNR is generally much higher than the surface stations, also exhibit better cor- 
relation with wind speeds in LR than with local wind speeds in Anza or with temperature measured inside the borehole.

To assess the effect of wind turbine activity in LR on regional stations, we examined the multiyear variation in daily median amplitudes at selected surface stations with good SNRs. To avoid data gaps, we extract for each station the peak value of daily medians of smoothed vertical ground-motion envelopes for 20- or 40-day windows. This allows us to obtain a continuous time series more amenable to spectral analysis.

Figure 7a,c,e,g shows the results of this analysis for data recorded before 2011 and after 2014 using peak values computed from 20-day windows at stations IKP, MONP2, and BOR, and from 40-day windows as station LVA2. Most of the stations show a strong annual peak during the winter and spring months, when wind speeds are largest. We compute the power spectral density (PSD) of the time series in Figure $7 \mathrm{a}, \mathrm{c}, \mathrm{e}, \mathrm{g}$ using multitaper spectrum analysis (Prieto et al., 2009; Krischer, 2016) and present in Figure 7b,d,f, $\mathrm{h}$ the PSD estimates and the $95 \%$ confidence intervals for each station. The annual modulation of high frequencies is manifested by the peak around 320-370 days in each of the periodograms. Remarkably, we find that the annual peaks in stations located tens of kilometers from LR are amplified after the LR wind farm-initiated operation. To illustrate this, we show in Figure 7b,d,f,h the spectral amplitudes of the 20-day peak of median daily values during a 6-yr period preceding the initiation of wind turbine activity in LR at stations installed on or before 2001. For the period between 2014 and 2018, sites MONP2, BOR, and LVA2 exhibit statistically significant $(p$ value $<0.001$ ) increase in annual peak median amplitudes relative to years preceding 2011 (when the first turbine in LR has been installed). At stations BOR and LV2, located 82 and $96 \mathrm{~km}$ from LR, respectively, we find that the annual peak median PSD amplitudes increase by a factor of 2-4 after 2014. Station MONP2, located $47 \mathrm{~km}$ away from LR, exhibits annual modulation before the installment of the LR wind farm, which is only modestly increased after 2014. It is possible that this station is also sensitive to local winds blowing near the station.

Analyzing the records measured in the Anza borehole sites in the same manner as the surface stations is difficult because of data gaps present in the borehole records. Instead, we analyze the correlation between 2 and $8 \mathrm{~Hz}, 24$-hr-long envelopes of vertical ground velocity measured in the borehole stations, and wind speed recorded in LR. Because daily energy production values for LR are not publicly available, we only analyze days when wind speeds exceeded $36 \mathrm{~km} / \mathrm{hr}$. We compute the envelopes by selecting a 24-hr window around the time of peak wind speed. The ground velocity in the selected time window is filtered between 2 and $8 \mathrm{~Hz}$, squared, and smoothed using a 20-min running mean window.

We use records obtained between 2009 and 2011, before the installation of wind turbines in LR, and between 2015 and 2017, after more than 50 turbines were installed at that site. All borehole stations show a positive correlation between ground velocity amplitudes and wind speed in LR for the time period between 2015 and 2017. A few stations also exhibit a slightly positive correlation for records obtained prior to 2011. However, the mean correlation values obtained for the period 2015-2017 exhibit a marginally significant ( $p$ value $<0.1$ ) increase relative to the mean correlation obtained for 2009-2011.

We used the recorded wind speed in Anza during the same time windows when strong winds were recorded in LR to verify that the increase in the correlation values after 2015 is not caused by changes in local wind speeds affecting the stations. We find that the correlation between vertical ground velocity amplitudes and wind speed in Anza did not exhibit a statistically significant increase after 2015 .

The modulation of seismic noise levels during strong winds could be the result of wind turbine activity in SGP. However, U.S. Energy Information Administration records indicate that by 2011 energy capacity in SGP reached $96 \%$ of the average capacity between 2012 and 2016 (the total number of turbines in SGP actually decreased during that period), and hence it is unlikely that activity at the SGP site may explain our observations. In addition, we could not find a significant difference in wind speeds in Anza from 2011 to 2018 that could explain the systematic increase in 1- to 8-Hz energy levels observed across the Anza region.

\section{Seismic Noise Induced by Traffic}

In addition to the transient signals produced by trains and wind farms, the borehole seismometers in the Anza region also show a peak in noise at about $3 \mathrm{~Hz}$, which appears to be present more or less continuously, with an amplitude variation that suggests a different, though still anthropogenic, source.

Figure 8 shows some of the relevant data. Figure $8 \mathrm{a}, \mathrm{b}$ shows power spectra for a horizontal component of two of the borehole sites. The spectrum estimation was done using the procedure of Barbour and Agnew (2012): the power spectrum was estimated every 18 min using a sine multitaper method followed by resampling of the spectrum at frequency points spaced roughly at logarithmic intervals (eight values per octave). The spectra shown are median values at each frequency either for all weekdays or for all nighttime periods. The difference shows a peak at about $3 \mathrm{~Hz}$ for weekday noise compared with that at night, even for B088, for which neither spectrum shows a peak. (E) Figure S5 shows similar plots for all working components of the Plate Boundary Observatory borehole seismometers, and it is clear that this variable peak is present on them all.

The reason for restricting one median to weekdays is shown in Figure 8c,d, which display the variation in power with time, modulo one week, integrated over the frequency band of this peak. These plots show a very clear day-night cycle, which might be thought to be meteorological if it did not shrink every weekend, with the values at midday on Sunday being roughly comparable to those at midnight during the week. A plot for all components at all stations (E) Fig. S6) shows that this variability is common to all stations. 

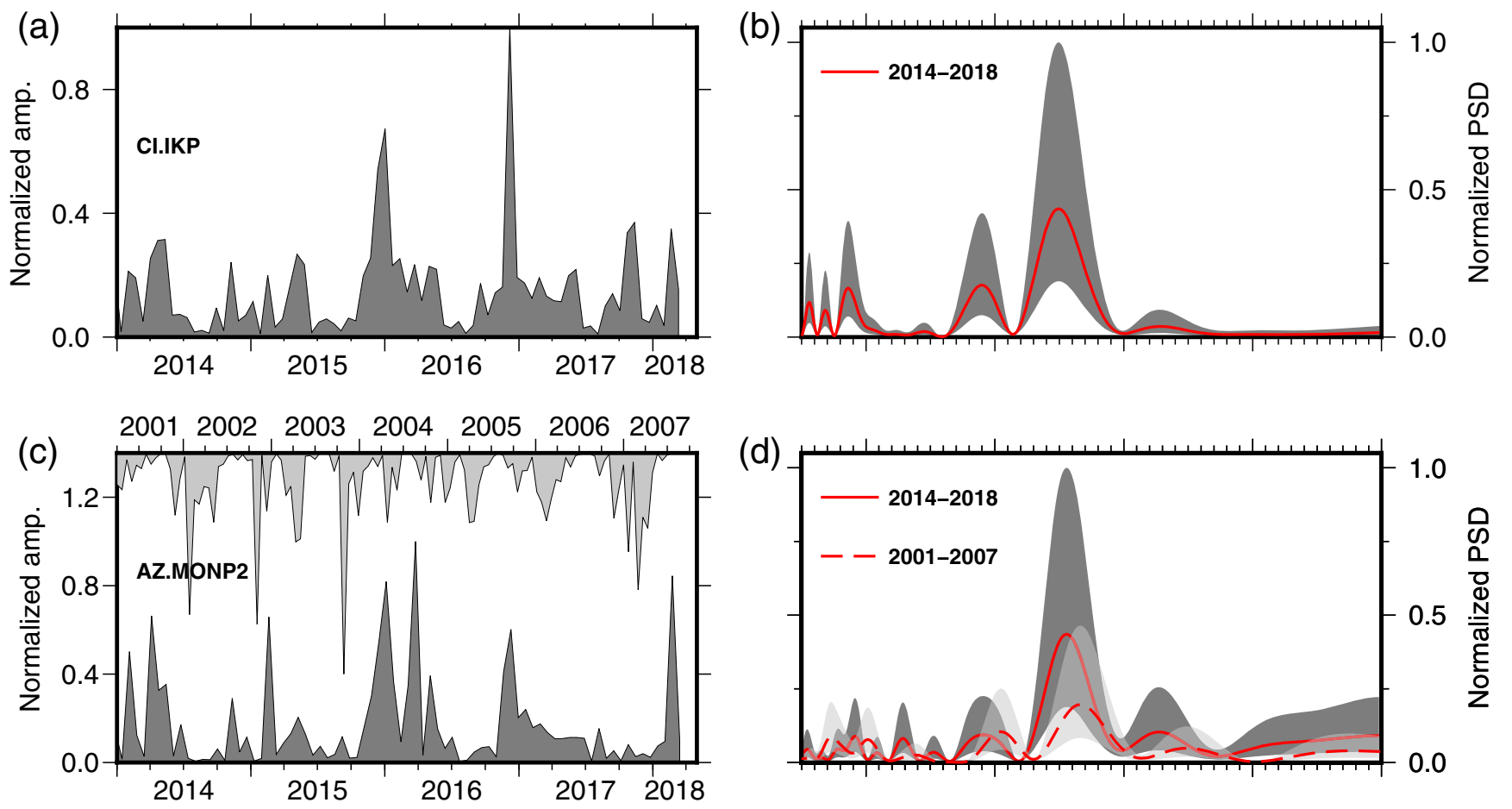

(d)

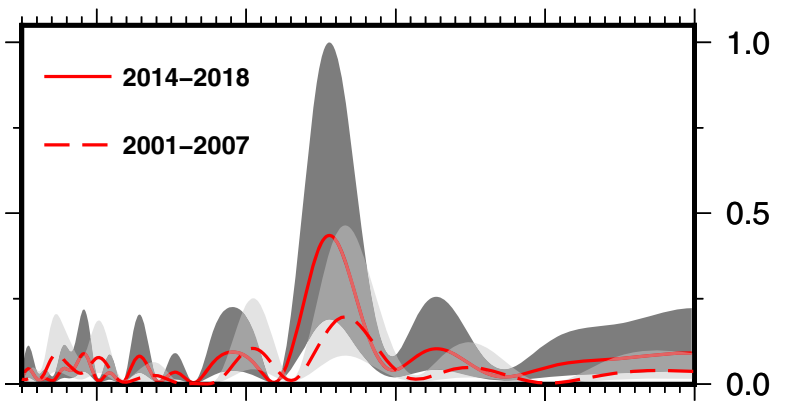

की
$\frac{1}{8}$
$\frac{N}{0}$
$\frac{N}{\sigma}$
$\frac{2}{2}$
$z$

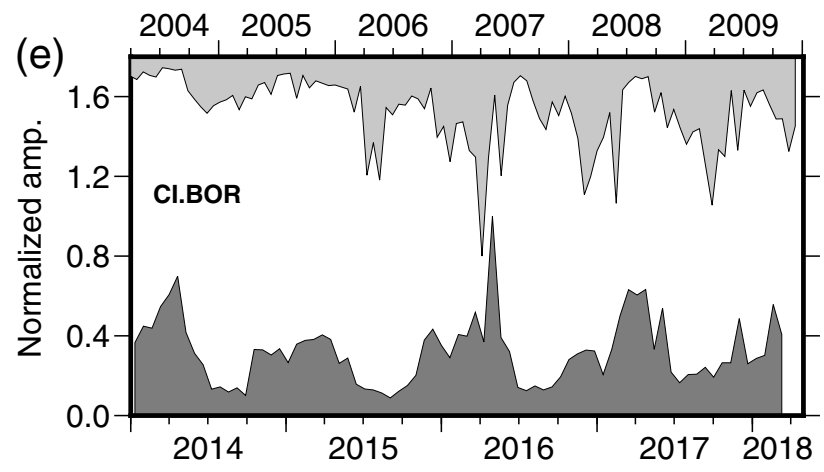

(f)
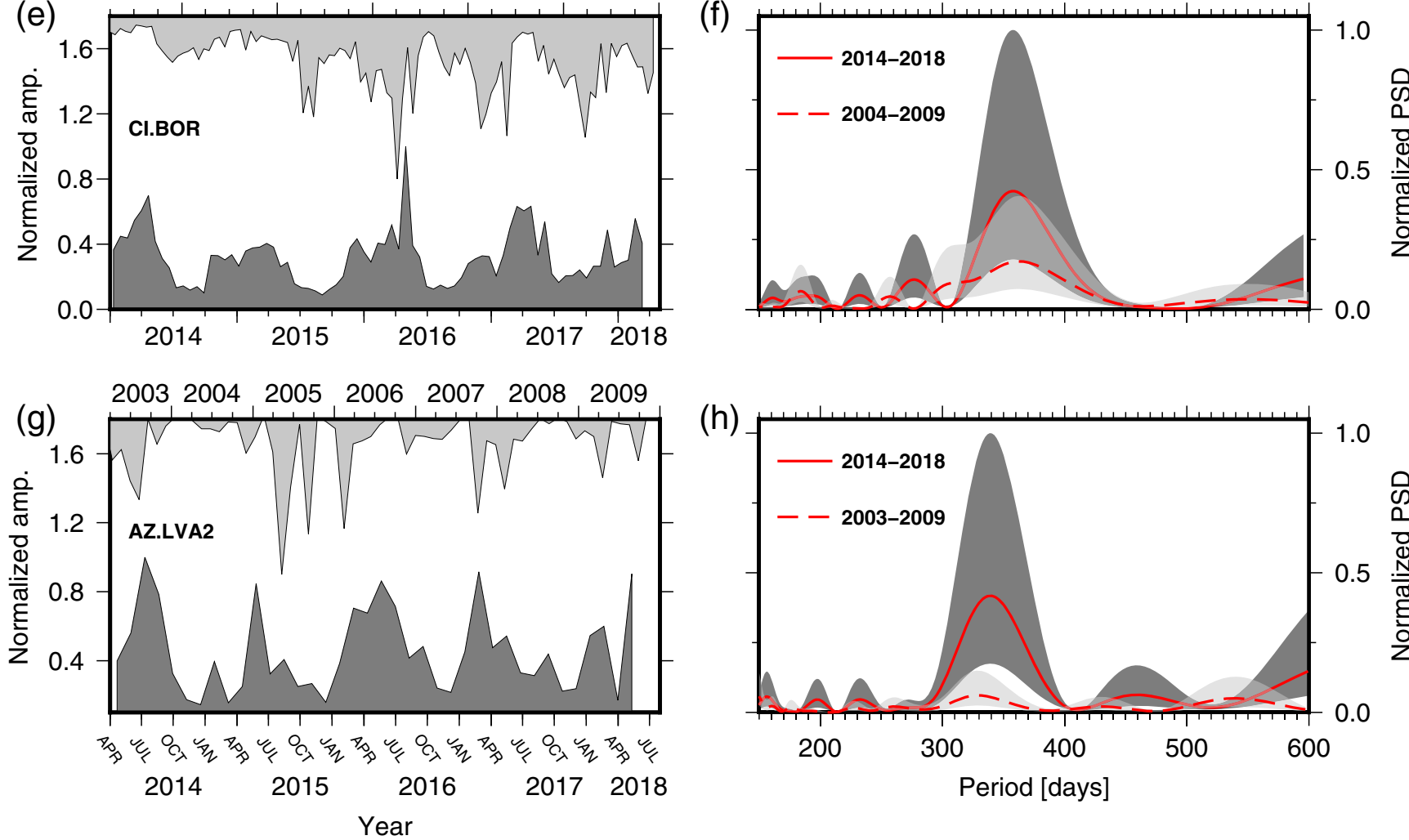

(h)

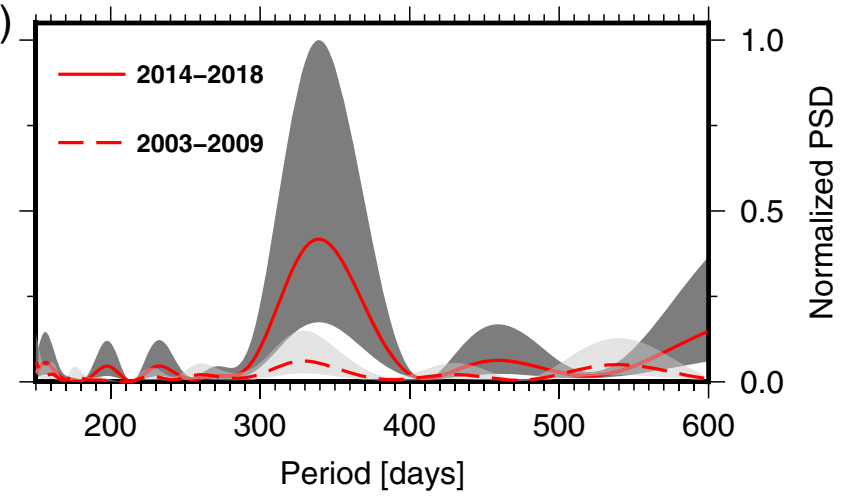

Figure 7. Temporal and spectral analysis of multiyear vertical ground velocity envelopes at selected stations in southern California. (a,c, e,g) Twenty-day maximum amplitude of daily medians as a function of time between 2014 and 2018 in dark gray. A multiyear period is shown in light gray for stations deployed before 2014 (with a reversed vertical axis spanning an equal scale as the one for amplitudes between 2014 and 2018). Station names are indicated in each panel. Amplitudes are normalized by the maximum value in each time series. (b,d,f,h) Normalized power spectral densities (PSDs) corresponding to the time series shown in (a,c,e,g). Solid and dashed curves are mean PSD for envelopes of data recorded after and before 2014, respectively. Gray regions denote $95 \%$ confidence intervals on the PSD estimates. PSDs were normalized by the maximum (within the confidence interval) PSD values for the 2014-2018 time interval. The color version of this figure is available only in the electronic edition. 


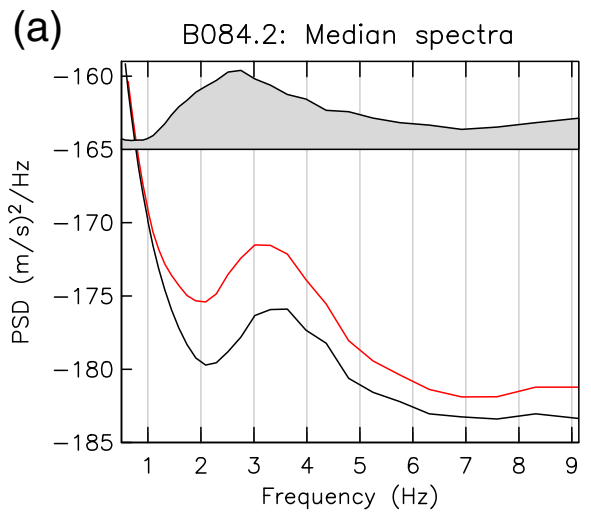

(b) B088.2: Median spectra

(c)

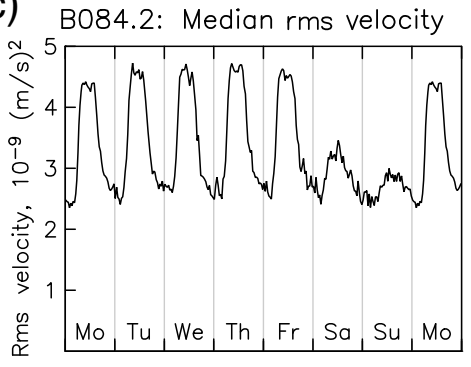

(e)

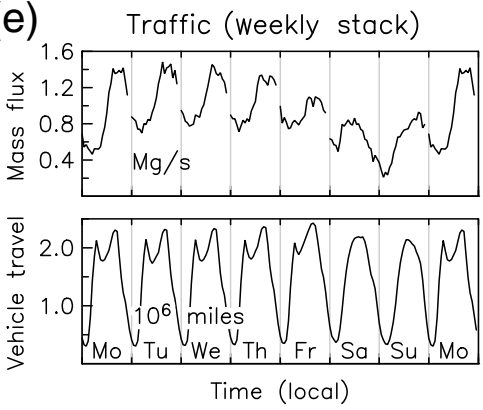

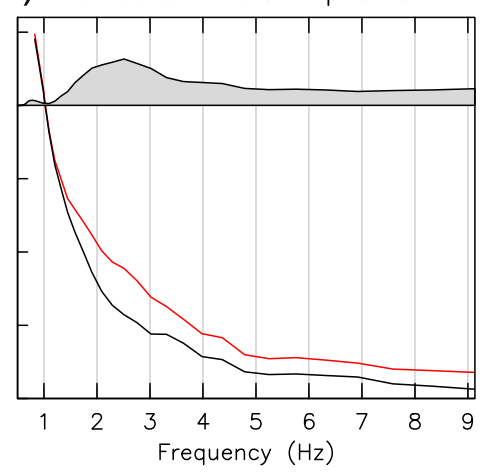

(d) RMS for $1.9-3.7 \mathrm{~Hz}$

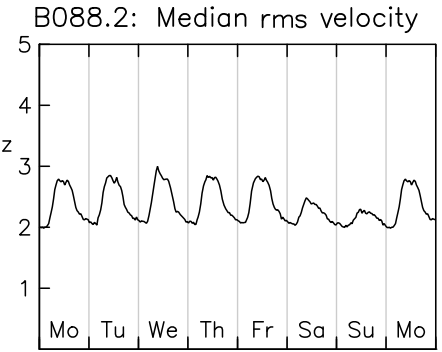

(f)

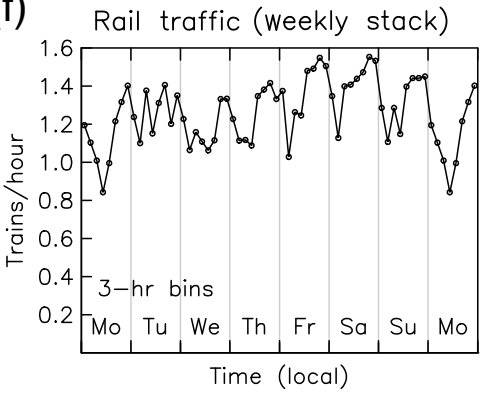

Figure 8. The properties of the 3-Hz hum observed on stations of the Plate Boundary Observatory (PBO) network in the Anza area along with possible sources. $(\mathrm{a}, \mathrm{b})$ Median power spectra of horizontal component 2 for two PBO sites; spectra were estimated using the method described in the Seismic Noise Induced by Traffic section. In each panel, the gray line shows the median spectrum for times from 09:00 to 15:00 (local time) on weekdays; the black line shows the median spectrum for times from 21:00 to 03:00 on all nights. The filled area shows the difference between these. (a) Station PB.B084. (b) Station PB.B088. (c,d) The time variation of the spectrum at station PB.B084 and PB.B088, integrated over frequencies from 1.7 to $3.9 \mathrm{~Hz}$, where the largest peak is. The values are medians for root mean square (rms) values binned at $36 \mathrm{~min}$ and folded to be days of the week; each median estimate is based on about 700 individual values. (c) Station PB.B084. (d) Station PB.B088. (e) Two measures of highway traffic: the bottom subpanel shows total vehicle miles traveled on state highways in Caltrans District 8 (Riverside and San Bernardino counties), and the top subpanel shows the truck traffic through a weighing station (Dillon Road) on I-10 (location shown in Fig. 1): both are hourly averages for the total over the time span of 1 March-9 April 2010 and for trucks over the time span of 18 March-20 April 2010. (f) Average rail traffic on the YSD of the Union Pacific Railroad based on detections at the Durmid Hill laser strainmeter for 2008-2011. The color version of this figure is available only in the electronic edition.

Both the day-night cycle and the weekend decrease are inconsistent with this steady noise being caused by rail traffic. As noted earlier, the details of this traffic are proprietary, but a very different geophysical measurement allows us to determine how it varies. The University of California at San Diego operates two long-base laser strainmeters less than $1 \mathrm{~km}$ from the YSD track and southwest of the Coachella valley. These instruments show a characteristic signature from passing trains caused by loading of the ground. We identified a number of such signals by manual scanning through the data and averaged them to construct a matched filter for detecting all rail traffic over a 4-yr span. Figure 8f shows that rail traffic shows neither a clear decrease at night nor one on the weekend, although there is a possible decrease on Mondays.

Daily variation of seismic noise, with lower values on weekends, has been seen before in seismic noise at frequencies of several Hz; for example, Yamanaka et al. (1993) observed it in Los Angeles, Groos and Ritter (2009) in Bucharest, BonnefoyClaudet et al. (2006) in Grenoble, and Hillers et al. (2012) in Taiwan. However, all of these observations came from urban areas: for example, there are two million people within $10 \mathrm{~km}$ of the site used by Yamanaka et al. (1993). B084, at Piñon Flat, has only about 2000 people living within the same distance, and B088 has even fewer (see (E) Fig. S7). It is surprising to observe a pattern usually associated with large numbers of people in a place where there are few to none.

A weekend decrease in anthropogenic noise may seem unproblematic in a city such as Bucharest, where the central regions are likely to be much less crowded than during the week. But the spatial uniformity of this pattern in the Anza area implies that whatever the noise source is, it must also be widespread. The most obvious choice is vehicle traffic, which certainly declines at night. But it does not on weekends. Figure 8e shows a stack of hourly data on total vehicle miles traveled in the urban areas nearest to Anza in early 2010: this series has a double peak during the week but an equally large single peak on both Saturday and Sunday.

Atef et al. (2009) noted this same difficulty in trying to explain the weekly variations in seismicity rate and concluded only that because traffic did not vary as needed, there must be some kind of general activity that did. One possibility is industrial machinery, but the Anza region is an open space, rural residential, and agriculture area without any large industrial plants.

One anthropogenic source with a pattern matching the seismic noise is a subset of vehicle traffic: large trucks. Fig- 
ure 8e also shows, from a Caltrans station near Indio, a weekly stack of several weeks of hourly data for truck traffic on the I-10 highway for the most common vehicle class (fiveaxle semitrailer); because both number of trucks and average weight are available, we computed a mass flux. This flux varies with time in much the same way that the seismic noise does, including drops in both quantities not just on weekends but also on holidays such as Memorial Day, which again have overall traffic levels comparable to weekdays.

Numerical models of vehicle-based vibrations (e.g., Lombaert and Degrande, 2003) show that these include two modes of vibration: one set, with frequencies from 1 to $3 \mathrm{~Hz}$, corresponds to translation and rotation of the frame, and another from 10 to $20 \mathrm{~Hz}$ corresponds to motions of the wheel-tire-shock-absorber system, known as wheel hop. The former corresponds to the spectral peak observed on the Anza borehole seismometers.

\section{Signals Identified by Hutchison and Ghosh (2017)}

To identify and locate spontaneous tectonic tremors in Anza, HG17 analyzed continuous time-series data from June 2011 recorded by permanent stations in Anza and by the three temporary arrays. In this time interval, all three arrays were operative. HG17 reports on five 2- to 3-min time windows during which they observe tremors that appear to originate from a deep source along the SJF. Next, we examine in detail their detection scheme, pointing out several assumptions that significantly reduce its robustness against traininduced signals recorded by the arrays or by the permanent network. We then reanalyze each of the time windows reported by HG17 to look for potential signals generated by trains moving along the railroad surrounding Anza.

HG17 lists several measures they take to prevent false detections of cultural noise sources. They state that traininduced signals in Anza last 15-20 min, generally longer than the 2-min episodes they identify as tectonic tremors occurring along the SJF. We find, however, that because of their emergent nature and low amplitudes, the exact origin and durations of these transients are difficult to determine and thus may have escaped the HG17 visual inspection. For example, we find that sources active along a different stretch of railroad (the Perris Valley subdivision of Metrolink, hereafter PVSD; indicated in Fig. 1a) give rise to bursts of energy in the target frequency band, which exceed the background noise level for periods as short as 1 or $2 \mathrm{~min}$ at stations located tens of kilometers from the source. Additionally, to avoid false detections caused by train-induced signals in the 3- to 4-Hz band, HG17 filters the data between 6 and $8 \mathrm{~Hz}$. Our analysis of train-induced signals originating from the Coachella Valley shows that their spectra in Anza is peaked between 3 and $4 \mathrm{~Hz}$ (Fig. 4a). Nonetheless, the amplitude of the largest train-induced signals originating from the PVSD or YSD may sometime exceed the 6- to 8-Hz noise level. From visual inspection of several windows containing transients, we find that Anza seismograms recording trains moving along the PVSD exhibit a distinguishable signal that persists after applying a 6- to $8-\mathrm{Hz}$ bandpass filter. Thus, the duration and filtering criteria used by HG17 may only unequivocally reject signals caused by trains moving along the YSD but not along the PVSD.

Windows that match the accepted duration criteria are further analyzed by HG17 using two different approaches. In the first approach, multibeam backprojection (MBBP; Ghosh et al., 2012) is used simultaneously with all three temporary arrays deployed in Anza (PFO, CA, and GA arrays; see Fig. 1b). The MBBP technique uses beamforming array analysis to resolve the slowness with each of the arrays. The source location is determined from the intersection of rays backprojected in 3D using the slowness obtained at each of the arrays. A true detection is declared when at least two of the arrays point to a deep source located along the SJF. We refer to the requirement that a source must be identified by at least two of the arrays as the two-array criterion.

The resolution limit of the arrays is determined by the array response function (Rost and Thomas, 2002) under the assumption of perfect wavefield coherence across the array. For a 2D array, these functions are characterized by a main lobe whose width is inversely proportional to the ratio between the array aperture to the characteristic wavelength of the incoming signal. The aperture of the temporary Anza arrays used by HG17 is small $(\sim 600 \mathrm{~m})$, and hence their angular resolution for coherent signals in the $2-$ to $8-\mathrm{Hz}$ frequency band is between $10^{\circ}$ and $50^{\circ}$. In practice, the twoarray criteria of HG17 allows them to distinguish between two sources only if these sources are separated by an angle that is larger than the angular resolution of at least one of the two arrays. For example, such is the case for the portion of the YSD to the north-northeast of Anza, where the back azimuth resolved by the GA and PFO arrays is sufficient to discriminate between sources located in the Coachella Valley from sources located along the SJF segment in Anza (Fig. 1a). However, the separation between potential sources located south of Anza and the target segment of the SJF is close to or even below the resolution limit of both the PFO and GA arrays. To safely reject a signal whose origin is to south-southeast of Anza, one must include back azimuths measured at array $\mathrm{CA}$ in conjunction with back azimuths at array GA or PFO. The case of the PVSD railroad is more difficult as it is near Anza, therefore potentially generating large signals, and is separated from the target fault segment by an angle that is close to the resolution limit of all three arrays. To safely reject signals caused by trains moving along that railroad, one must also include information from more distant stations. Thus, the two-array criterion of HG17 is effective for discarding signals from trains moving along the YSD, may also work for sources located to south of Anza only if one of the two back-azimuth measurements is obtained by the CA array, and is insufficient for discarding signals caused by trains moving along the PVSD.

In principle, a second reliable measure against false detections of shallow cultural sources is the observed apparent 
velocity, which should approximate the local wavespeeds in each site for wavefronts leaving shallow sources and impinging on the array at near-horizontal incidence angles. We find, however, that during transients that originate from shallow sources, resolved apparent velocities in isolated windows may appear to be consistent with a deep source (Figs. 3d, 4, and 5 in HG17). To overcome this difficulty, one should analyze the mean apparent velocity over several consecutive time windows, thus ensuring the transient-averaged apparent velocity across the array is within the range expected from a source at depth.

The second approach used by HG17 as a complement to the MBBP is an ECC technique (e.g., Wech and Creager, 2008). In this procedure, the source may be crudely located using differential arrival times obtained by cross-correlating waveform envelopes recorded in a regional network. HG17 cautiously considers detections only if both the ECC and the MBBP approaches yield similar results. However, the resolution of the ECC approach is severely limited by the station distribution in Anza. Because of interstation distances that are small relative to the distance to the remote cultural sources giving rise to low-amplitude transients, surface-wave arrival lag times between Anza borehole stations are short, typically within a few seconds. Computing signal envelopes involves smoothing, which further reduces temporal resolution to the point that waves generated by a distant shallow source located tens of kilometers from Anza appear to arrive at several of the local stations at once (E) Fig. S1). This configuration poses a major difficulty for methods relying on ECC to detect and locate tremors.

Deep sources located along the SJF are expected to give rise to signals with lag times between the Anza borehole stations that are easily below the resolution of envelope-based techniques. Given the frequent occurrence, spectral content, duration, and amplitude of train-induced signals in Anza, using envelope-based techniques on local stations will likely result in many false detections, even if reasonable steps are taken to avoid them. One alternative is to smooth the envelopes using a short $(<2 \mathrm{~s})$ window. This solution is not optimal because it may result in misidentifying many local and regional events as tremor. As we will show, a second, much simpler solution is to include regional stations located near the railroads surrounding Anza. Because train-induced signals are easily recognizable on traces recorded less than $50 \mathrm{~km}$ from the source, regional stations outside Anza and borehole stations located near the SJF can be simultaneously used to effectively reject transients whose envelope-derived differential arrival times in near-SJF stations appear to be consistent with a deep source located along the SJF.

In light of its design, we expect the HG17 approach to yield many false detections despite their efforts to prevent this. Figures 9 and 10 present ground motions recorded on 10 and 8 June 2011, respectively. Both these time windows were reported by HG17 to contain signals from a deep tremor source located along the SJF (see figs. S7 and S6 in HG17). Traces in Figure 9 were bandpass filtered between 2 and $5 \mathrm{~Hz}$, squared, and smoothed using a 0.5 -s median window. The moveout of motions recorded by regional permanent stations are consistent with seismic waves propagating from a source located to the northwest (Fig. 9) or south (Fig. 10) of Anza and not with a source located along the SJF. It is most likely that a train moving along the PVSD railroad (Fig. 1a) on 10 June 2011 gave rise to the signal observed in Anza. A separate detection on 22 June 2011, reported by HG17 to contain signals from tremors along the SJF (see fig. 4 in HG17), but that shows a clear moveout consistent with a source moving along the PVSD is presented in (E) Figure S8.

We find that peak amplitudes at site PLS, located nearest the railroad, are a factor of 1.2-2.9 smaller than at station MUR located farther southeast but that peak amplitudes measured over a distance of $90 \mathrm{~km}$ to the southeast of the tracks decay by roughly a factor 10 , as expected from surface waves generated from a source located on the tracks. A tremor source located in the Anza section of the SJF is expected to produce signals that decay in the northwest direction toward the PVSD railroad, which is inconsistent with our observations (Fig. 9 and (E) Fig. S8). Because of the distribution of stations around the PVSD and the high levels of noise present in seismograms in that part of Riverside, tracking a train moving along that railroad is more difficult than along the YSD. Thus, the slight deviation from expected amplitudes for stations near the track may be simply because the trains were not accurately located or because of conditions affecting sites PLS or MUR.

The arrivals presented in Figure 10 are caused by a unregistered regional event located in Baja California. Unfortunately, the small number of stations in that area prevents us from determining the epicentral location of this 22 June 2011 event. However, Figure 10 clearly shows that the arrivals identified by HG17 cannot be associated with an event in Anza. Presumably, the high apparent velocity of seismic phases at regional distances gave rise to apparent velocities consistent with the deep source reported by HG17.

In two other dates reported by HG17, we do not observe a signal that may be easily associated with a source outside Anza as in the case of the transients on 8, 10, and 22 June 2011. We examined the traces recorded by the Anza borehole stations during the 1 and the 6 June 2011 transients reported by HG17. Because of their superb SNR and given that they lie in close proximity to the area HG17 indicate is the tremor source region, the Anza borehole stations should clearly exhibit signatures of any tremor-related signal detected with the temporary arrays. Visual inspection of seismograms at these sites during the intervals reported by HG17 do not reveal any signal that may be associated with tremor ( $(E)$ Figs. S9 and S10), and we therefore regard them as false detections. The 1 June 2011 transient is indeed visible on stations of the CA and GA arrays (but not by the borehole stations). However, the arrival lag time between these two arrays is inconsistent with a deep source located along the SJF and is thus likely due to a single shallow source or multiple uncorrelated shallow sources. 


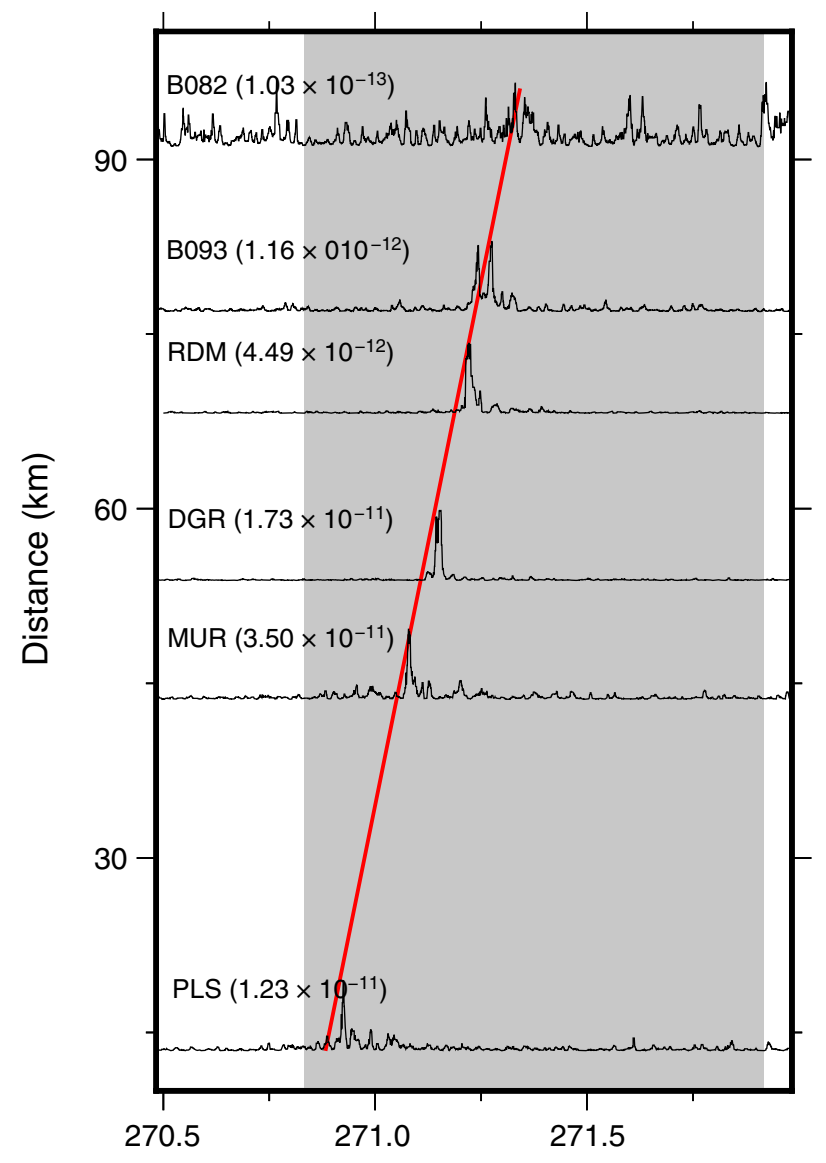

Minutes since 2011-06-10 00:00:00 UTC

Figure 9. Envelopes of vertical ground motions as a function of time (UTC) caused by a source active on 10 June 2011. Traces are sorted according to their distance from the PVSD railroad (location indicated in Fig. 1a). Stations names and squared peak ground velocity amplitudes $\left(\mathrm{cm}^{2} / \mathrm{s}^{2}\right)$ are indicated above each trace. Diagonal line indicates propagation velocity of $3 \mathrm{~km} / \mathrm{s}$. Gray area indicates the window Hutchison and Ghosh (2017) identify as containing deep tectonic tremors occurring on the SJF (tremor source region determined by Hutchison and Ghosh, 2017 is indicated by the ellipse in Fig. 1b). The color version of this figure is available only in the electronic edition.

To summarize, we find no evidence for tectonic tremor activity during any of the dates reported by HG17. On three of these dates, we find clear evidence that signals associated by HG17 with deep tectonic tremors occurring along the SJF actually originated from shallow remote sources located $50-100 \mathrm{~km}$ from Anza or are caused by a regional earthquake. Two other reported detections do not give rise to a discernible signal at borehole stations located within about $10 \mathrm{~km}$ from the SJF, and hence we consider them false detections.

\section{Discussion and Conclusions}

Vibrations from truck and train traffic along the Coachella Valley, a major transportation artery, appear to be the primary source of seismic noise at roughly $1-5 \mathrm{~Hz}$ in the Anza region. These traffic signals are low amplitude (relative to the

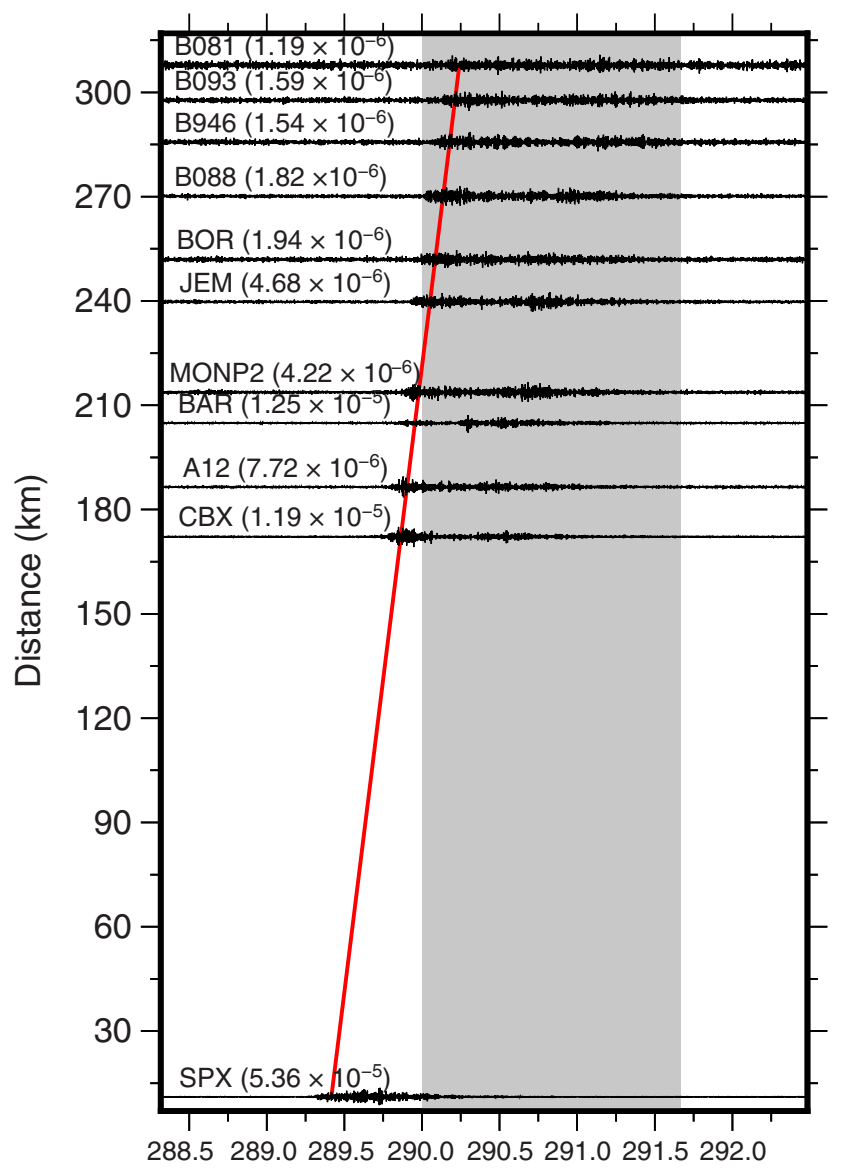

Minutes since 2011-06-08 00:00:00 UTC

Figure 10. Vertical ground motions as a function of time (UTC) caused by a regional unregistered event that occurred in southern Baja California on 8 June 2011. Stations are sorted according to their distance from an arbitrary point just south of station BC.SPX in Baja California, the southernmost station that recorded this event. Diagonal line indicates propagation velocity of $6 \mathrm{~km} / \mathrm{s}$. Stations names and peak ground velocity $(\mathrm{cm} / \mathrm{s})$ are indicated above each trace. Other symbols are as in Figure 9. The color version of this figure is available only in the electronic edition.

background noise level) and difficult to distinguish in the time domain at the noisier surface stations but are readily detected by dense arrays and are more clearly seen on Anza borehole instruments. Using data from borehole Anza stations as well as surface CI stations along the Coachella Valley, we show that trains running along the YSD in the Coachella Valley in proximity to station MGE and along the PVSD generate vibrations that are associated with visually detectable transients at most of the borehole sites. We determined that the transients are associated with train traffic, but the sustained hum is associated with truck traffic. Both forms of seismic noise have similar frequency-domain signatures. We believe there is a simple reason for this: the natural frequency $f$ of a mass-spring system is related to its static deflection $d$ under gravity: $d=g / 4 \pi^{2} f^{2}$. A frequency of $3 \mathrm{~Hz}$ corresponds to $d=2.7 \mathrm{~cm}$ (about $1 \mathrm{inch}$ ). It seems reasonable to assume that the suspensions of both railcars and trucks are designed to 
allow comparable static deflections. We thus conclude that both trains and trucks generate the predominate 2- to $5-\mathrm{Hz}$ noise observed across the Anza array, with trains moving along the YSD generating visually apparent transients with durations on the order of $20 \mathrm{~min}$. Trains moving along the PVSD railway may give rise to visually detectable transients with duration that is on the order of $5 \mathrm{~min}$.

The Anza stations are expected to be sensitive to operations in the SGP wind farm, the largest wind farm in southern California ( $>2000$ wind turbines). Instead, we find that the construction of about 50 towers at the LR wind farm in northern Baja California caused a significant increase in the amplitude of 1- to 5-Hz noise present in the Anza stations between 2014 and 2018. Most stations show very weak seasonal modulation before 2011 , although by that time, more than 2000 of the SGP wind turbines were already in place. The radius influenced by operations at LR wind is surprisingly large and extends out to about $100 \mathrm{~km}$. It is possible that wind farm-induced signal generated at SGP decays rapidly with distance traveled within the soft sediments of the Coachella Valley. Favorable wind conditions and the wind turbine's proximity to the bedrock underlying the Sierra Juárez range in LR are most likely the reason wind turbines in LR are capable of inducing such loud transients. Plans to increase the number of wind turbines in LR from 50 to 500 in the coming years are expected to degrade the capability for monitoring of weak tectonic transients in Anza.

The traffic-induced transients are strong enough to generate correlated noise envelopes across the Anza borehole array within the 2 - to $8-\mathrm{Hz}$ frequency band, lasting a up to a few tens of minutes (Fig. 3). Moreover, the transients consist of near-repeats of highly similar short-duration waveforms (E) Fig. S2) because of the localized nature of the sources (small size relative to wavelength). Because these features are similar to those of tectonic tremor signals, the train-induced signals can effectively masquerade as tectonic tremor. Thus, these signals were identified using a tremor-detection approach designed based on characteristics of tremor observed elsewhere. The ubiquitous nature of the identified noise sources in the Coachella Valley is likely one of the reasons why tectonic tremor has been difficult to observe along the SJF; the other possible reason is that perhaps it simply does not occur. In any case, our results place bounds on the capability to detect spontaneous tremors in southern California with current instrumentation and analysis techniques. Our characterization of the noise will be useful to develop tremor detection algorithms that are not fooled by cultural noise sources that have confounded previous approaches.

We examined the dates when HG17 reported tectonic tremors that occurred along the SJF. Despite their efforts to prevent false detections, we find that during three of the five transients identified by HG17, the moveout across regional surface and borehole stations is more consistent with cultural or natural sources that are not located along the SJF. The transients on 10 and 22 June 2011 are most likely caused by a freight train moving along the PVSD, and the transient on
8 June 2011 is caused by an unregistered regional event in Baja California. Two other transients on 1 and 6 June 2011 do not give rise to signals that can be readily identified in the seismograms recorded by borehole stations located in Anza. Given the superb SNR (in time windows not containing traininduced transients) of the tremor target frequency band at the borehole stations and given that at least two of the stations are located at shorter distance to the tremor source region than any of the temporary arrays used to detect them, the lack of a clear signal suggests that the transients on 1 and 6 June 2011 reported were incorrectly identified as tremor.

Although our analysis reveals an anthropogenic origin of the transient signals observed at Anza, these waveform data, which we have shown can be traced to identifiable (moving) sources, can be used to improve the shallow attenuation model for the region. The skin depth of the inferred high-frequency surface waves generated by trains is in between the depths accessible to boreholes and the depth range over which conventional seismological investigations provide resolution. Simplified calculations presented in this study reveal that $Q$ increases more strongly with depth than suggested by coarser models inferred from analysis of seismic data. Similar studies exploiting high-frequency ground motion induced by traffic could be undertaken in regions of low-seismicity rate to complement the earthquake hazard assessment of critical facilities.

\section{Data and Resources}

Seismic data used in this study were recorded and maintained by the Anza seismic network (doi: http://dx.doi.org/10 .7914/SN/AZ), the Southern California Seismic Network (doi: http://dx.doi.org/10.7914/SN/CI), the Plate Boundary Observatory Borehole Seismic Network (http://www.fdsn.org /networks/detail/PB), and the Red Sísmica del Noroeste de México (doi: http://dx.doi.org/10.7914/SN/BC). The MAOTECTRA array data are available at doi: http://dx.doi.org/ 10.7914/SN/ZZ_2011. The laser strainmeter data are available at https://www.unavco.org/data/strain-seismic/lsm-data/lsmdata.html. Traffic data are from the Caltrans Performance Measurement System at http://pems.dot.ca.gov. Wind speed data are from UNAVCO at http://www.unavco.org and from the National Climatic Data Center at https://www.ncdc.noaa .gov. Wind energy data are from the California Energy Commission at http://energy.ca.gov/almanac/renewables_data/ wind and the U.S. Energy Information Association at https ://www.eia.gov/electricity/data/eia860. The La Rumorosa report by the State of California Public Utilities Commission is available at cpuc.ca.gov. Data were last accessed March 2018.

\section{Acknowledgments}

The authors thank D. Shelly, A. Barbour, N. Lindsey, and an anonymous reviewer for thoughtful reviews that improved this article. A. Inbal wishes to thank R. C. Escamilla for pointing out the La Rumorosa wind farm project as a potential source of seismic noise in Anza and A. Vidal and A. Nuñez from the Centro de Investigación Cientifica y de Educacion 
Superior de Ensenada Baja California for their help. Part of A. Inbal's work was done during a visit to Caltech supported by a scholarship from Ben Gurion University of the Negev, Israel, and by a Fulbright scholarship. Part of A. Inbal's work at the University of California, Berkeley, was supported by a fellowship from the Israeli Minister of Energy and Water. T. CristeaPlaton's work was supported by the Caltech SURF Program. The MAOTECTRA deployment was funded by U.S. Geological Survey (USGS) Award G11AP20056. This work was partially funded by National Science Foundation (NSF) Grant Number EAR-1015698 and by the Southern California Earthquake Center (SCEC; Contribution Number 8204). SCEC is funded by NSF Cooperative Agreement EAR-1033462 and USGS Cooperative Agreement G12AC20038.

\section{References}

Aki, K., M. Fehler, and S. Das (1977). Source mechanism of volcanic tremor: Fluid-driven crack models and their application to the 1963 Kilauea eruption, J. Volcanol. Geoth. Res. 2, no. 3, 259-287, doi: 10.1016/0377-0273(77)90003-8.

Anderson, J. G., and S. E. Hough (1984). A model for the shape of the Fourier amplitude spectrum of acceleration at high frequencies, Bull. Seismol. Soc. Am. 74, no. 5, 1969-1993.

Ariyoshi, K., T. Matsuzawa, J.-P. Ampuero, R. Nakata, T. Hori, Y. Kaneda, R. Hino, and A. Hasegawa (2012). Migration process of very lowfrequency events based on a chain-reaction model and its application to the detection of preseismic slip for megathrust earthquakes, Earth Planets Space 64, no. 8, 693-702, doi: 10.5047/eps.2010.09.003.

Atef, A. H., K. H. Liu, and S. S. Gao (2009). Apparent weekly and daily earthquake periodicities in the western United States, Bull. Seismol. Soc. Am. 99, no. 4, 2273-2279, doi: 10.1785/0120080217.

Barbour, A. J., and D. C. Agnew (2012). Detection of seismic signals using seismometers and strainmeters, Bull. Seismol. Soc. Am. 102, no. 6, 2484-2490, doi: 10.1785/0120110298.

Bonnefoy-Claudet, S., F. Cotton, and P.-Y. Bard (2006). The nature of noise wavefield and its applications for site effects studies: A literature review, Earth Sci. Rev. 79, 205-227, doi: 10.1016/j.earscirev.2006.07.004.

Caffagni, E., D. Eaton, M. van der Baan, and J. P. Jones (2015). Regional seismicity: A potential pitfall for identification of long-period longduration events, Geophysics 80, no. 1, A1-A5, doi: 10.1190/geo20140382.1 .

Campbell, K. W. (2009). Estimates of shear-wave $Q$ and $\kappa_{0}$ for unconsolidated and semiconsolidated sediments in eastern North America, Bull. Seismol. Soc. Am. 99, no. 4, 2365-2392, doi: 10.1785/0120080116.

Dou, S., N. Lindsey, A. M. Wagner, T. M. Daley, B. Freifeld, M. Robertson, J. Peterson, C. Ulrich, E. R. Martin, and J. B. Ajo-Franklin (2017). Distributed acoustic sensing for seismic monitoring of the near surface: A traffic-noise interferometry case study, Sci. Rep. 7, no. 1, Article Number 11620, doi: 10.1038/s41598-017-11986-4

Fletcher, J. B., T. Fumal, H.-P. Liu, and L. C. Carroll (1990). Near-surface velocities and attenuation at two boreholes near Anza, California, from logging data, Bull. Seismol. Soc. Am. 80, no. 4, 807-831.

Fletcher, J. B., P. Spudich, and L. M. Baker (2006). Rupture propagation of the 2004 Parkfield, California, earthquake from observations at the UPSAR, Bull. Seismol. Soc. Am. 96, no. 4B, S129-S142, doi: 10.1785/0120050812.

Frankel, A., S. Hough, P. Friberg, and R. Busby (1991). Observations of Loma Prieta aftershocks from a dense array in Sunnyvale, California, Bull. Seismol. Soc. Am. 81, no. 5, 1900-1922.

Fry, B., K. Chao, S. Bannister, Z. Peng, and L. Wallace (2011). Deep tremor in New Zealand triggered by the $2010 M_{\mathrm{w}} 8.8$ Chile earthquake, Geophys. Res. Lett. 38, no. 15, doi: 10.1029/2011GL048319.

Fuchs, F., and G. Bokelmann (2018). Equidistant spectral lines in train vibrations, Seismol. Res. Lett. 89, no. 1, 56-66, doi: 10.1785/ 0220170092.

Ghosh, A., J. E. Vidale, and K. C. Creager (2012). Tremor asperities in the transition zone control evolution of slow earthquakes, J. Geophys. Res. 117, no. B10, doi: 10.1029/2012JB009249.
Gibbons, S. J., and F. Ringdal (2006). The detection of low magnitude seismic events using array-based waveform correlation, Geophys. J. Int. 165, no. 1, 149-166, doi: 10.1111/j.1365-246X.2006.02865.x.

Gomberg, J., J. L. Rubinstein, Z. Peng, K. C. Creager, J. E. Vidale, and P. Bodin (2008). Widespread triggering of nonvolcanic tremor in California, Science 319, no. 5860, 173, doi: 10.1126/science.1149164.

Groos, J. C., and J. R. R. Ritter (2009). Time domain classification and quantification of seismic noise in an urban environment, Geophys. J. Int. 179, no. 2, 1213-1231, doi: 10.1111/j.1365-246X.2009.04343.x.

Hillers, G., M. Campillo, Y. Lin, K. Ma, and P. Roux (2012). Anatomy of the high-frequency ambient seismic wave field at the TCDP borehole, $J$. Geophys. Res. 117, no. B6, doi: 10.1029/2011JB008999.

Hough, S. E., and J. G. Anderson (1988). High-frequency spectra observed at Anza, California: Implications for $Q$ structure, Bull. Seismol. Soc. Am. 78, no. 2, 692-707.

Hutchison, A. A., and A. Ghosh (2017). Ambient tectonic tremor in the San Jacinto fault, near the Anza gap, detected by multiple mini seismic arrays, Bull. Seismol. Soc. Am. 107, no. 5, 1985-1993, doi: 10.1785/ 0120160385 .

Hutton, K., J. Woessner, and E. Hauksson (2010). Earthquake monitoring in southern California for seventy-seven years (1932-2008), Bull. Seismol. Soc. Am. 100, no. 2, 423-446, doi: 10.1785/0120090130.

Ide, S., D. R. Shelly, and G. C. Beroza (2007). Mechanism of deep low frequency earthquakes: Further evidence that deep non-volcanic tremor is generated by shear slip on the plate interface, Geophys. Res. Lett. 34, no. 3, doi: 10.1029/2006GL028890.

Inbal, A., J.-P. Ampuero, and J.-P. Avouac (2017). Locally and remotely triggered aseismic slip on the central San Jacinto fault near Anza, CA, from joint inversion of seismicity and strainmeter data, $J$. Geophys. Res. 122, no. 4, doi: 10.1002/2016JB013499.

Inbal, A., J. P. Ampuero, and R. W. Clayton (2016). Localized seismic deformation in the upper mantle revealed by dense seismic arrays, Science 354, no. 6308, 88-92, doi: 10.1126/science.aaf1370.

Krischer, L. (2016). mtspec Python Wrappers 0.3.2, doi: 10.5281/ zenodo.321789.

Latorre, D., A. Amato, M. Cattaneo, S. Carannante, and A. Michelini (2014). Man-induced low-frequency seismic events in Italy, Geophys. Res. Lett. 41, no. 23, 8261-8268, doi: 10.1002/2014GL062044.

Li, C., Z. Li, Z. Peng, C. Zhang, N. Nakata, and T. Sickbert (2018). Longperiod long-duration events detected by the IRIS community wavefield demonstration experiment in Oklahoma: Tremor or train signals?, Seismol. Res. Lett. doi: 10.1785/02201080081.

Lombaert, G., and G. Degrande (2003). The experimental validation of a numerical model for the prediction of the vibrations in the free field produced by road traffic, J. Sound Vib. 262, no. 2, 309-331, doi: 10.1016/S0022-460X(02)01048-9.

Marcillo, O. E., and J. Carmichael (2018). The detection of wind-turbine noise in seismic records, Seismol. Res. Lett. 89, no. 5, 1826-1837, doi: 10.1785/0220170271.

Meng, H., and Y. Ben-Zion (2018). Characteristics of airplanes and helicopters recorded by a dense seismic array near Anza California, J. Geophys. Res. 123, no. 6, 4783-4797, doi: 10.1029/ 2017JB015240.

Meng, X., and Z. Peng (2014). Seismicity rate changes in the Salton Sea geothermal field and the San Jacinto fault zone after the 2010 $M_{\mathrm{w}} 7.2$ El Mayor-Cucapah earthquake, Geophys. J. Int. 197, no. 3, 1750-1762, doi: $10.1093 /$ gji/ggu085.

Nadeau, R. M., and D. Dolenc (2005). Nonvolcanic tremors deep beneath the San Andreas fault, Science 307, no. 5708, 389, doi: 10.1126/ science.1107142.

Nakata, N., R. Snieder, T. Tsuji, K. Larner, and T. Matsuoka (2011). Shear wave imaging from traffic noise using seismic interferometry by crosscoherence, Geophysics 76, no. 6, SA97-SA106, doi: 10.1190/ geo2010-0188.1.

Neuffer, T., and S. Kremers (2017). How wind turbines affect the performance of seismic monitoring stations and networks, Geophys. J. Int. 211, no. 3, 1319-1327, doi: 10.1093/gji/ggx370. 
Obara, K. (2002). Nonvolcanic deep tremor associated with subduction in southwest Japan, Science 296, no. 5573, 1679-1681, doi: 10.1126/science. 1070378.

Peng, Z., and K. Chao (2008). Non-volcanic tremor beneath the Central Range in Taiwan triggered by the $2001 M_{\mathrm{w}} 7.8$ Kunlun earthquake, Geophys. $J$. Int. 175, no. 2, 825-829, doi: 10.1111/j.1365-246X.2008.03886.x.

Peng, Z., J. E. Vidale, A. G. Wech, R. M. Nadeau, and K. C. Creager (2009). Remote triggering of tremor along the San Andreas fault in central California, J. Geophys. Res. 114, no. B7, doi: 10.1029/ 2008JB006049.

Prieto, G., R. Parker, and F. Vernon (2009). A Fortran 90 library for multitaper spectrum analysis, Comput. Geosci. 35, no. 8, 1701-1710, doi: 10.1016/j.cageo.2008.06.007.

Qin, L., Y. Ben-Zion, H. Qiu, P.-E. Share, Z. E. Ross, and F. L. Vernon (2018). Internal structure of the San Jacinto fault zone in the trifurcation area southeast of Anza, California, from data of dense seismic arrays, Geophys. J. Int. 213, no. 1, 98-114, doi: 10.1093/gji/ggx540.

Quiros, D. A., L. D. Brown, and D. Kim (2016). Seismic interferometry of railroad induced ground motions: Body and surface wave imaging, Geophys. J. Int. 205, no. 1, 301-313, doi: 10.1093/gji/ggw033.

Riahi, N., and P. Gerstoft (2015). The seismic traffic footprint: Tracking trains, aircraft, and cars seismically, Geophys. Res. Lett. 42, no. 8, 2674-2681, doi: 10.1002/2015GL063558.

Rost, S., and C. Thomas (2002). Array seismology: Methods and applications, Rev. Geophys. 40, no. 3, 1008, doi: 10.1029/2000RG000100.

Rubinstein, J. L., D. R. Shelly, and W. L. Ellsworth (2009). Non-volcanic tremor: A window into the roots of fault zones, in New Frontiers in Integrated Earth Sciences, Springer, Dordrecht, The Netherlands, 287-314, doi: 10.1007/978-90-481-2737-5_8.

Saccorotti, G., D. Piccinini, L. Cauchie, and I. Fiori (2011). Seismic noise by wind farms: A case study from the Virgo Gravitational Wave Observatory, Italy, Bull. Seismol. Soc. Am. 101, no. 2, 568, doi: 10.1785/ 0120100203.

Sanders, C. O., and H. Kanamori (1984). A seismotectonic analysis of the Anza Seismic Gap, San Jacinto fault zone, southern California, J. Geophys. Res. 89, no. B7, 5873-5890, doi: 10.1029/ JB089iB07p05873.

Schofield, R. (2001). Seismic measurements at the Stateline Wind Project, Tech. Rept. Number LIGO T020104-x0, Laser Interferometer Gravitational Wave Observatory, available at https://dcc.ligo.org/T020104/ public (last accessed February 2018).

Shelly, D. R., and J. L. Hardebeck (2010). Precise tremor source locations and amplitude variations along the lower-crustal central San Andreas fault, Geophys. Res. Lett. 37, no. 14, doi: 10.1029/ 2010 GL043672.

Shelly, D. R., G. C. Beroza, and S. Ide (2007). Non-volcanic tremor and lowfrequency earthquake swarms, Nature 446, no. 7133, 305-307, doi: 10.1038/nature05666.

Shelly, D. R., G. C. Beroza, S. Ide, and S. Nakamula (2006). Low-frequency earthquakes in Shikoku, Japan, and their relationship to episodic tremor and slip, Nature 442, no. 7099, 188-191, doi: 10.1038/ nature 04931.

Thatcher, W., J. A. Hileman, and T. C. Hanks (1975). Seismic slip distribution along the San Jacinto fault zone, southern California, and its implications, Geol. Soc. Am. Bull. 86, 1140-1146, doi: 10.1130/ 0016-7606(1975)86<1140:SSDATS >2.0.CO;2.

Wang, T.-H., E. S. Cochran, D. Agnew, and D. D. Oglesby (2013). Infrequent triggering of tremor along the San Jacinto fault near Anza, California, Bull. Seismol. Soc. Am. 103, no. 4, 2482-2497, doi: 10.1785/0120120284.

Wech, A. G., and K. C. Creager (2008). Automated detection and location of Cascadia tremor, Geophys. Res. Lett. 35, no. 20, doi: 10.1029/ 2008GL035458.

Wech, A. G., C. M. Boese, T. A. Stern, and J. Townend (2012). Tectonic tremor and deep slow slip on the Alpine fault, Geophys. Res. Lett. 39, no. 10, doi: 10.1029/2012GL051751.
Wesnousky, S. G. (1994). The Gutenberg-Richter or characteristic earthquake distribution, which is it?, Bull. Seismol. Soc. Am. 84, no. 6, 1940-1959.

Yamanaka, H., M. Dravinski, and H. Kagami (1993). Continuous measurements of microtremors on sediments and basement in Los Angeles, California, Bull. Seismol. Soc. Am. 83, no. 5, 1595-1609.

Yang, W., E. Hauksson, and P. M. Shearer (2012). Computing a large refined catalog of focal mechanisms for southern California (1981-2010): Temporal stability of the style of faulting, Bull. Seismol. Soc. Am. 102, no. 3, 1179-1194, doi: 10.1785/0120110311.

Zecevic, M., G. Daniel, and D. Jurick (2016). On the nature of longperiod long-duration seismic events detected during hydraulic fracturing, Geophysics 81, no. 3, KS113-KS121, doi: 10.1190/ geo2015-0524.1.

Department of Geophysics

Tel Aviv University

Ramat-Aviv, 69978 Tel-Aviv, Israel

asafinbal@tauex.tau.ac.il

(A.I.)

Department of Mathematics

Massachusetts Institute of Technology (MIT)

Headquarters Office Simons Building (Building 2)

Room 106, 77 Massachusetts Avenue

Cambridge, Massachusetts 02139-4307

tudor.cristea.platon@gmail.com

(T.C.-P.)

Université Côte d'Azur, IRD, CNRS

Observatoire de la Côte d'Azur

UMR Géoazur-Campus Azur du CNRS

250 rue Albert Einstein

CS 10269

F 06905 Sophia Antipolis, Cedex

France

ampuero@gps.caltech.edu

(J.-P.A.)

Institute of Seismology

University of Helsinki

PL 68 (Gustaf Hällströmin katu 2b)

Helsinki 00014, Finland

gregor.hillers@helsinki.fi

(G.H.)

Scripps Institution of Oceanography

University of California, San Diego

9500 Gilman Drive, 0225

La Jolla, California 92093

dagnew@ucsd.edu

(D.A.)

U.S. Geological Survey

525 South Wilson Avenue

Pasadena, California 91106-3212

hough@usgs.gov

(S.E.H.)

Manuscript received 28 April 2018;

Published Online 16 October 2018 